Alloys and Compounds

Elsevier Editorial System(tm) for Journal of

Manuscript Draft

Manuscript Number: JALCOM-D-19-00907R1

Title: Upconversion luminescence in transparent oxyfluoride glass ceramics containing hexagonal NaErF4

Article Type: Full Length Article

Keywords: upconversion;

oxyfluoride;

site-selective spectroscopy;

glass ceramics;

NaErF 4

Corresponding Author: Miss Guna Krieke,

Corresponding Author's Institution: Institute of Solid State Physics

First Author: Guna Krieke

Order of Authors: Guna Krieke; Andris Antuzevics, Dr.Phys; Maris Springis, Dr.Phys; Uldis Rogulis, Dr.Phys

Abstract: Transparent oxyfluoride glass ceramics containing hexagonal NaErF4 nanocrystals were synthesized by a heat treatment of a precursor glass obtained by the melt quenching technique. Combined X-ray diffraction (XRD) and transmission electron microscopy (TEM) analysis revealed the formation of single phase nanocrystals in the glass ceramics. The enhancement of intensity and spectral change of upconversion luminescence (UCL) confirmed the presence of Er3+ ions in the crystalline phase of the glass ceramics. Dominant energy transfer processes were identified using the rate equation formalism. Timeresolved site-selective spectroscopy studies at low temperatures were employed to elucidate the local structure of Er3+ ions in the glass ceramics and microcrystalline NaErF4. The origin of multi-site formation in hexagonal NaErF4 lattice is discussed. 


\section{COVER LETTER}

Dear Editor,

Please, accept the manuscript "Upconversion luminescence in transparent glass ceramics containing hexagonal $\mathrm{NaErF}_{4}$ " for publication in The Journal of Alloys and Compounds.

The article is original, has been written by the stated authors who are all aware of its content and approve its submission, has not been published previously, it is not under consideration for publication elsewhere, no conflict of interest exists.

If accepted, the article will not be published elsewhere in the same form, in any language, without the written consent of the publisher. The submission of this manuscript to your journal has been accepted the approval from all of other coauthors. 
Prime Novelty Statement

For the first time crystallization, upconversion luminescence, dominant energy transfer processes and erbium ion local environment of transparent oxyfluoride glass ceramics containing hexagonal $\mathrm{NaErF}_{4}$ is reported. 
Dear reviewer,

Thank you for your time and efforts spent during the revision of the manuscript.

We believe, that your recommendations will improve the quality of the manuscript. The changes made in the manuscript are highlighted.

The detailed response to the comments raised in your revision is given below.

Reviewer \#1: In this manuscript, the authors presented the preparation, characterization and luminescence properties of Er3+ doped silicate glasses containing NaErF4 derived from heattreatment of the precursor glasses. From the scientific and technical qualities of the manuscript, I recommend accepting it for publication after major revision.

1/ The paper title should be revised. The glass host, namely oxyfluoride silicate glass should be mentioned.

The title of the manuscript has been revised.

2/ The "Results and discussion" section should be separated into several sub-sections and each sub-section should be numbered.

The section "Results and discussion" has been divided in appropriate sub-sections.

3/ The X-ray wavelength used for XRD pattern measurements should be given since the diffraction patterns depend on the $X$-ray wavelength. The Sherrer equation used for estimating the particles size should be given since the equation can be presented in different forms.

The wavelength of used X-ray source is now shown in the text as the average wavelength of $\mathrm{Cu} \mathrm{K}_{\alpha 1}$ and $\mathrm{K}_{\alpha 2}$. The Scherrer equation, which takes in account instrumental line broadening, is now added in the manuscript.

4/ More detailed processes for getting the data in Table 1 should be given.

Calculations of non-radiative transition probabilities are now described in more detail including the determination of multiphonon relaxation rates and an example of balance rate equation.

5/ In general, the English is $\mathrm{OK}$, but it needs further careful revision to meet the publication standard.

Minor grammar and spelling mistakes are now corrected in the text. 


\title{
Upconversion luminescence in transparent oxyfluoride glass ceramics containing hexagonal $\mathrm{NaErF}_{4}$
}

Guna Krieke*, Andris Antuzevics, Maris Springis, Uldis Rogulis

Institute of Solid State Physics, University of Latvia, 8 Kengaraga str., LV-1063, Riga, Latvia.

*Corresponding author, guna.krieke@ cfi.lu.lv, +371 28260803

\begin{abstract}
Transparent oxyfluoride glass ceramics containing hexagonal $\mathrm{NaErF}_{4}$ nanocrystals were synthesized by a heat treatment of a precursor glass obtained by the melt quenching technique. Combined X-ray diffraction (XRD) and transmission electron microscopy (TEM) analysis revealed the formation of single phase nanocrystals in the glass ceramics. The enhancement of intensity and spectral change of upconversion luminescence (UCL) confirmed the presence of $\mathrm{Er}^{3+}$ ions in the crystalline phase of the glass ceramics. Dominant energy transfer processes were identified using the rate equation formalism. Time-resolved site-selective spectroscopy studies at low temperatures were employed to elucidate the local structure of $\mathrm{Er}^{3+}$ ions in the glass ceramics and microcrystalline $\mathrm{NaErF}_{4}$. The origin of multi-site formation in hexagonal $\mathrm{NaErF}_{4}$ lattice is discussed.
\end{abstract}

KEYWORDS: upconversion, oxyfluoride, site-selective spectroscopy, glass ceramics, $\mathrm{NaErF}_{4}$.

\section{Introduction}

Lanthanide ion doping is one of the general strategies in the development of luminescent materials. In case the targeted functionality of the material is upconversion luminescence (UCL), a process of lower energy photon conversion into photons with a higher energy, rare earth (RE) ions with ladder-like energy level arrangements, such as $\mathrm{Er}^{3+}, \mathrm{Yb}^{3+}, \mathrm{Tm}^{3+}$ and $\mathrm{Tb}^{3+}$, should be introduced to the host [1]. The highest UCL quantum yield values have been reported for erbium doped materials [2], therefore these systems are of a particularly high interest for applications in the fields of photonics, photovoltaics and medicine [3-9].

The main requirements for a highly efficient UCL process are low phonon energy of the host matrix and availability of low symmetry positions for activator ions in the lattice. $\mathrm{NaREF}_{4}$ 
compounds, cubic $\alpha-\mathrm{NaREF}_{4}$ and hexagonal $\beta-\mathrm{NaREF}_{4}$, are ideally suited UCL phosphor candidates [10-12]. First, the low phonon energies of fluorides compared to oxides minimize the rate of non-radiative transitions [13]. Secondly, the low symmetry positions of the lowtemperature hexagonal polymorph $\beta-\mathrm{NaREF}_{4}$ enhance the transition probabilities of the partly forbidden $4 \mathrm{f}-4 \mathrm{f}$ transitions [14]. As the result, the UCL efficiency of RE doped $\beta-\mathrm{NaREF}_{4}$ is estimated to be several orders of magnitude higher compared to $\alpha-\mathrm{NaREF}_{4}$ [15]. Unfortunately, synthesis of bulk single crystal $\beta-\mathrm{NaREF}_{4}$ is not always feasible. However, these phases can be stabilized, if they are integrated into a medium with a superior chemical and mechanical durability.

Oxyfluoride glass ceramics are composite materials, which consist of a fluoride crystalline phase distributed in an oxide glass [16]. Transparency characteristic of glasses can be maintained in glass ceramics by careful control of precipitated nanostructures. Preferential incorporation of activator ions into the low phonon fluoride phase of the nanocomposite may lead to a luminescence performance comparable to the respective single crystal.

Glass ceramics containing hexagonal $\mathrm{NaLaF}_{4}[17,18], \mathrm{NaGdF}_{4}[19,20]$ and $\mathrm{NaYF}_{4}[21,22]$ have been reported and examined previously. The luminescence intensity of the glass ceramics in comparison to that of the precursor glass was enhanced up to several orders of magnitude indicating an efficient incorporation of lanthanide activator ions in the crystalline phase.

In the family of $\mathrm{NaREF}_{4}$ compounds $\mathrm{NaErF}_{4}$ is particularly interesting because of erbium based hosts exhibiting red UCL, which is advantageous for applications in bioimaging and therapeutics. Additionally, erbium possesses a large intrinsic magnetic moment enabling a multi-functional use of $\mathrm{NaErF}_{4}$ nanoparticles as contrast agents in magnetic resonance imaging (MRI) [23,24]. However, a notable drawback from the high erbium content is the severe energy loss caused by the concentration quenching. Luminescence losses can be mitigated by doping $\mathrm{NaErF}_{4}$ with impurity ions, such as $\mathrm{Mn}^{2+}[25], \mathrm{Yb}^{3+}[24], \mathrm{Gd}^{3+}[26]$, or by implementing $\mathrm{NaErF}_{4}$ in core-shell nanostructures [27-30].

Because of the multisite nature of the lattice, a complete characterization of luminescence processes and energy transfer in $\beta-\mathrm{NaErF}_{4}$ is complicated and requires additional spectroscopic investigations. Furthermore, to our best knowledge, synthesis of glass ceramics containing single phase $\beta-\mathrm{NaErF}_{4}$ has not been realized yet. 
In the present paper we report the crystallization of $\beta-\mathrm{NaErF}_{4}$ in oxyfluoride glass ceramics. Luminescence properties of the glass ceramics were investigated in detail and compared with polycrystalline $\beta-\mathrm{NaErF}_{4}$.

\section{Materials and methods}

Precursor glass with chemical composition of $18 \mathrm{Na}_{2} \mathrm{O}-9 \mathrm{NaF}-8 \mathrm{ErF}_{3}-6 \mathrm{Al}_{2} \mathrm{O}_{3}-59 \mathrm{SiO}_{2}$ (in mol\%) was prepared by the conventional melt quenching method. A batch of $10 \mathrm{~g}$ was melted in covered corundum crucible at $1500^{\circ} \mathrm{C}$ for $30 \mathrm{~min}$ and afterwards casted in a stainless steel mould.

Glass ceramics were obtained after isothermal heat treatment of the precursor glass at $600^{\circ} \mathrm{C}$ for $10 \mathrm{~h}$.

The microcrystalline single phase $\beta-\mathrm{NaErF}_{4}$ was prepared using hydrothermal synthesis adapted from Ref. [31].

The X-ray diffraction data were obtained by PANalytical X'Pert Pro diffractometer using $\mathrm{Cu}$ $\mathrm{K}_{\alpha}$ tube $(\lambda=1.54 \AA)$ operated at $40 \mathrm{kV}$ and $30 \mathrm{~mA}$. The average size of the nanocrystals is estimated using the Scherrer equation:

$D=\frac{K \cdot \lambda}{\beta \cdot \cos \theta}$

where $\mathrm{D}$ is average crystallite size, $\mathrm{K}$ is crystallite shape factor ( 0.9 for spherical particles), $\lambda$ is wavelength of $\mathrm{X}$-ray tube, $\theta$ is angle of incidence and $\beta$ is structural broadening, which is the difference observed and instrumental broadening.

The microstructure of glass ceramics was characterized by transmission electron microscopy (TEM). Finely ground glass ceramic powder was dispersed in isopropanol and transferred to TEM grid. The measurements were performed with TEM Tecnai G2 F20 operated at $200 \mathrm{kV}$.

Luminescence was excited by a wavelength tuneable pulsed solid state laser Ekspla NT342/3UV and temperature controlled continuous wave (CW) laser diode $(\lambda=975 \mathrm{~nm})$. The emission signal was detected by Andor DU-401-BV CCD camera coupled to Andor SR-303iB spectrometer. Luminescence kinetics were measured using a photomultiplier tube and digital oscilloscope Tektronix TDS 684A. Low temperature measurements were performed 
using Advanced Research Systems DE202 N cold finger type He cryostat. Effective luminescence decay time was calculated as a weighted average of kinetics [32].

\section{Results and discussion}

\section{General characterization}

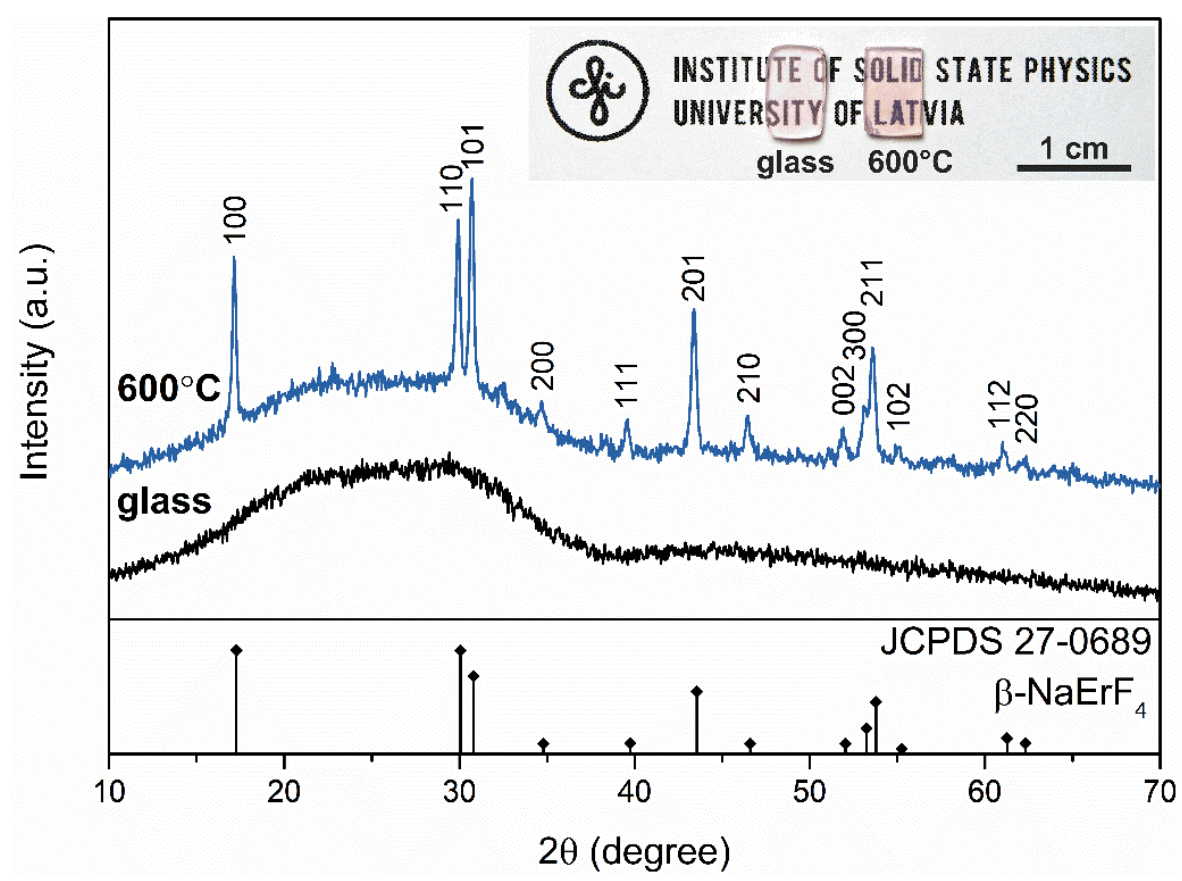

Fig. 1 XRD patterns of precursor glass and glass ceramics heat treated at $600^{\circ} \mathrm{C}$ for $10 \mathrm{~h}$ Inset: photograph of glass and transparent glass ceramic samples

XRD patterns of precursor glass and glass-ceramics after heat treatment at $600^{\circ} \mathrm{C}$ for $10 \mathrm{~h}$ are shown in Fig. 1. The precursor glass was X-ray amorphous. After the heat treatment intense diffractions peaks assigned to hexagonal $\mathrm{NaErF}_{4}$ were detected. The average size of the nanocrystals estimated using the Scherrer equation was approximately $40 \mathrm{~nm}$. Because of the small size of nanocrystals the glass ceramics retained the transparency (see the inset of Fig. 1). 

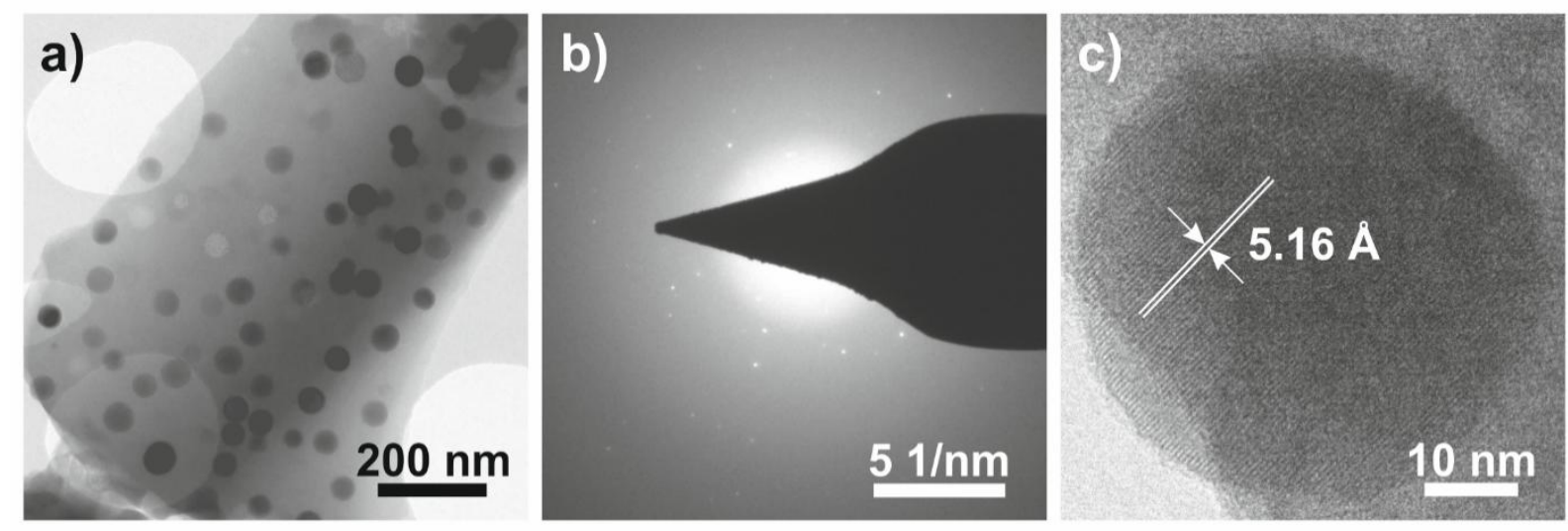

Fig. 2 a) and c) TEM micrographs, b) selected area electron diffraction pattern of glass ceramics heat treated at $600^{\circ} \mathrm{C}$ for $10 \mathrm{~h}$

TEM micrographs of glass ceramics heat treated at $600^{\circ} \mathrm{C}$ for 10 hare shown in the Fig. 2. Spherical particles were homogeneously distributed in the glass matrix (see Fig. 2 a)). The selected area electron diffraction pattern shown in the Fig. 2 b) contained broad halo characteristic to the amorphous structure. In addition, bright spots could be observed indicating presence of crystalline structure. The average size of particles was $42 \pm 10 \mathrm{~nm}$, which within the margin of error agrees well with the average crystallite size calculated from the Xray diffraction data. The high-resolution TEM characterization revealed that the individual particles were single-crystalline with uniform lattice fringes. The interplanar distance of individual crystal shown in the Fig. 2 c) is $5.16 \AA \mathrm{nm}$, which can be ascribed to the (100) plane of $\beta-\mathrm{NaErF}_{4}$.

\section{UCL spectroscopy}



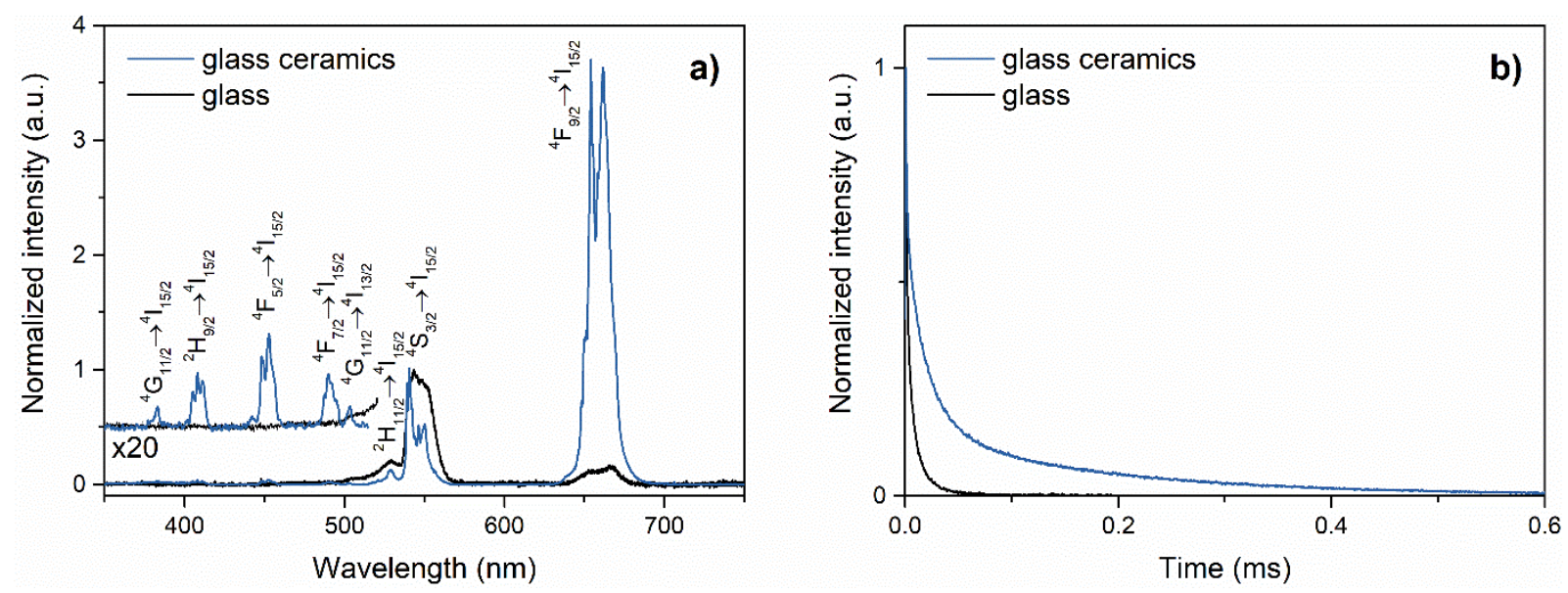

Fig. 3 a) UCL spectra normalized for the green emission and b) UCL kinetics of the green emission of glass and glass ceramics excited with $971 \mathrm{~nm}$

The Fig. 3 a) represents UCL spectra of the precursor glass and glass ceramics excited with $971 \mathrm{~nm}$. The most intense emission bands located 525, 545 and $650 \mathrm{~nm}$ were assigned to ${ }^{2} \mathrm{H}_{11 / 2} \rightarrow{ }^{4} \mathrm{I}_{15 / 2} ;{ }^{4} \mathrm{~S}_{3 / 2} \rightarrow{ }^{4} \mathrm{I}_{15 / 2}$ and ${ }^{4} \mathrm{~F}_{9 / 2} \rightarrow{ }^{4} \mathrm{I}_{15 / 2}$ transitions of $\mathrm{Er}^{3+}$ ions. In the precursor glass broad UCL bands characteristic to $\mathrm{Er}^{3+}$ ions in amorphous environment were observed. After the formation of $\beta-\mathrm{NaErF}_{4}$ the splitting of luminescence bands indicated the incorporation of $\mathrm{Er}^{3+}$ ions in the crystalline lattice. In addition, a considerable increase of lifetimes of emitting states was observed due to reduction of non-radiative multi-phonon relaxations (see Fig. 3 b)). As the result the UCL emission was enhanced and the intensity of UCL in glass ceramics was estimated to be one order of magnitude higher in comparison to precursor glass. Several additional bands assigned to ${ }^{4} \mathrm{G}_{11 / 2} \rightarrow{ }^{4} \mathrm{I}_{15 / 2},{ }^{2} \mathrm{H}_{9 / 2} \rightarrow{ }^{4} \mathrm{I}_{15 / 2},{ }^{4} \mathrm{~F}_{5 / 2} \rightarrow{ }^{4} \mathrm{I}_{15 / 2},{ }^{4} \mathrm{~F}_{7 / 2} \rightarrow{ }^{4} \mathrm{I}_{15 / 2}$ and ${ }^{4} \mathrm{G}_{11 / 2} \rightarrow{ }^{4} \mathrm{I}_{13 / 2}$ transitions originating from three photon UCL were detected in the glass ceramics. UCL excitation and experimentally observed radiative transitions are represented in the partial energy level diagram shown in the Fig. 4. 


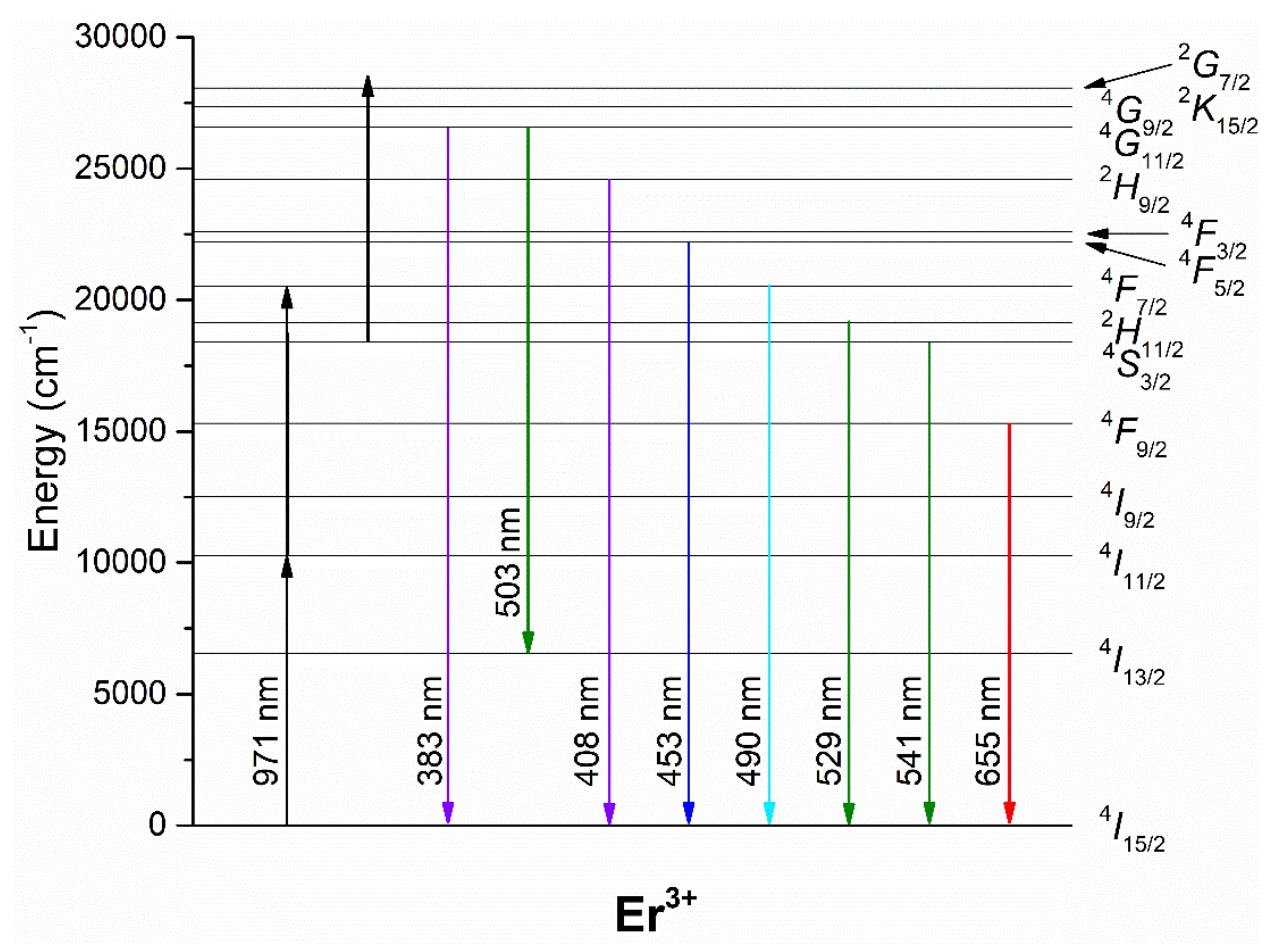

Fig. 4 Partial energy level diagram of $\mathrm{Er}^{3+}$ ions; UCL excitation and experimentally observed radiative transitions

In the precursor glass predominantly non-radiative multiphonon relaxations from the excited states can be expected due to relatively high phonon energy of glass matrix resulting in the population of the green $\left({ }^{2} \mathrm{H}_{11 / 2},{ }^{4} \mathrm{~S}_{3 / 2}\right)$ and the red $\left({ }^{4} \mathrm{~F}_{9 / 2}\right)$ emitting states. However, in glass ceramics intense red UCL was detected. The multiphonon relaxation from ${ }^{4} \mathrm{~S}_{3 / 2}$ to ${ }^{4} \mathrm{~F}_{9 / 2}$ is not efficient in fluoride hosts [9]; therefore, cross-relaxation should contribute to the population of the red emitting state.

Luminescence processes in $\beta-\mathrm{NaErF}_{4}$ containing the glass ceramics can be expected to be similar to single phase microcrystalline $\beta-\mathrm{NaErF}_{4}$ due to identic ionic distances characteristic to the crystalline lattice. In order to investigate the non-radiative processes in glass ceramics, UCL kinetics of $\beta-\mathrm{NaErF}_{4}$ containing glass ceramics were compared with single phase microcrystalline $\beta-\mathrm{NaErF}_{4}$. 


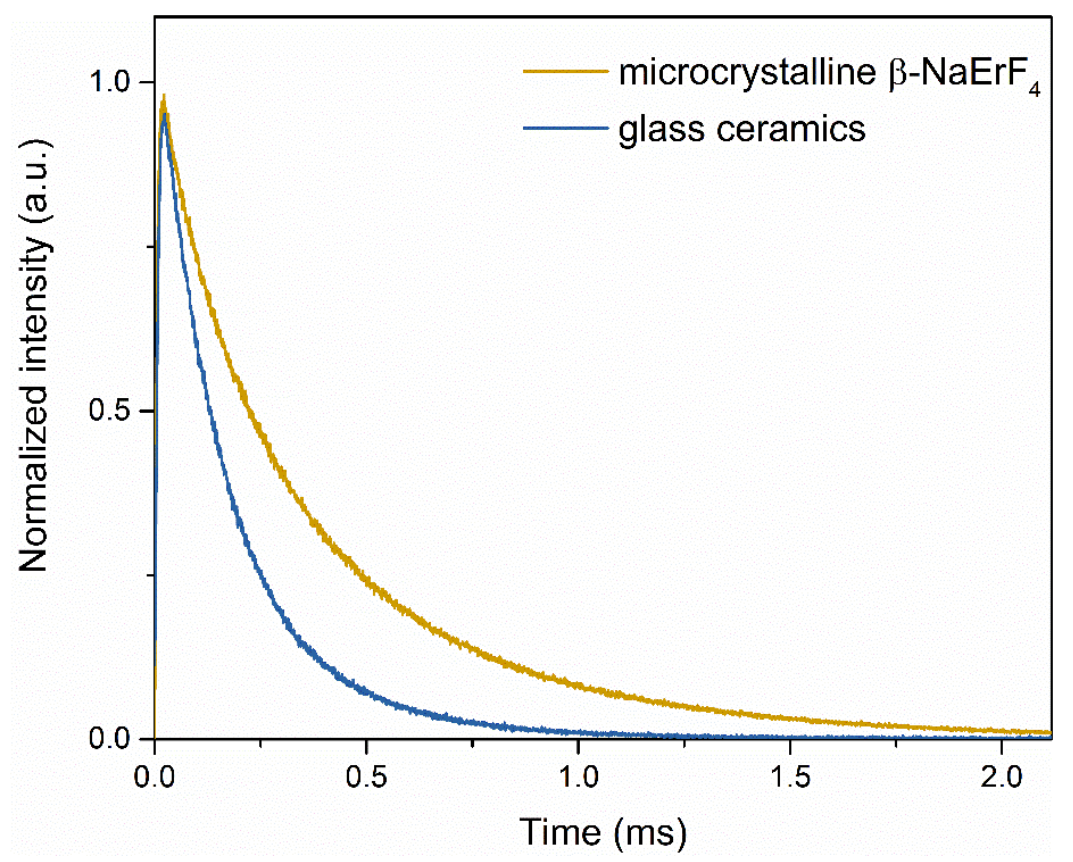

Fig. 5 UCL kinetics of the red emission excited with $971 \mathrm{~nm}$ in microcrystalline $\beta-\mathrm{NaErF}_{4}$ and glass ceramics

A comparison of UCL kinetics of red emission in single phase microcrystalline $\beta-\mathrm{NaErF}_{4}$ and glass ceramics is shown in the Fig. 5. The effective decay time of red emission was considerably longer in the microcrystalline sample $(0.44 \mathrm{~ms})$ than in the glass ceramics $(0.22$ $\mathrm{ms})$. Similar effect was observed for green emission with a decrease of the effective decay time from $0.24 \mathrm{~ms}$ in the microcrystalline sample to $0.14 \mathrm{~ms}$ in the glass ceramics. The reduction of the effective decay time indicated the presence of additional non-radiative decay pathways in the glass ceramics. The cross-relaxation parameters can be expected identic in both samples due to identic $\mathrm{Er}^{3+}$ content and crystalline structure in $\beta-\mathrm{NaErF}_{4}$ crystals; however, in nanocrystalline glass ceramics luminescence quenching on nanocrystal and glass matrix interface or energy transfer from crystalline phase to the glass matrix can be expected. We assume that both of these processes reduce the decay time of UCL luminescence in glass ceramics. Therefore, luminescence kinetics of the microcrystalline sample were analysed to determine the dominant cross-relaxation processes in $\beta-\mathrm{NaErF}_{4}$.

\section{Population dynamics of UCL luminescence}

We have studied theoretically and experimentally the population dynamics of $\mathrm{Er}^{3+}$ levels under selective excitation of ${ }^{4} \mathrm{I}_{11 / 2} \mathrm{Er}^{3+}$ level by short laser pulse $\left(\lambda_{\text {exc }}=971 \mathrm{~nm}\right)$. The energy transfer 
rates were calculated using the balance rate equation formalism described in Ref. [33,34]. In the system of balance rate equations ground state and eight lowest energy levels were considered and numbered from ground level in ascending order. For each level the possible population and depopulation processes as probabilities of radiative transitions, including branching factors, probabilities of multiphonon nonradiative transitions, and possible crossrelaxation and upconversion rates were considered. The probabilities of radiative transitions and branching ratios were taken from Ref. [35,36]. Probabilities of multiphonon nonradiative transitions were calculated for corresponding energy gap $\Delta E i j$ between adjacent levels and effective phonon energy of $\beta-\mathrm{NaErF}_{4}\left(360 \mathrm{~cm}^{-1}\right)$ as described in Ref. [37]. As an example, the balance rate equation for the level $5\left({ }^{4} \mathrm{~F}_{9 / 2}\right)$ is:

$\frac{d n_{5}}{d t}=-\sum w_{5 j} n_{5}-\omega_{54} n_{5}+\left(w_{65}+\omega_{65}\right) n_{6}+\gamma_{2} n_{2} n_{3}+\alpha_{2} n_{1} n_{9}-\alpha_{3} n_{1} n$,

where $n_{i}$ are the normalized populations of $\mathrm{Er}^{3+}$ level " $i$ ”; $w_{i j}\left(\mathrm{~s}^{-1}\right)$ are the probabilities of the radiative transitions " $i \rightarrow j$ "; $\square i j\left(\mathrm{~s}^{-1}\right)$ are the probabilities of nonradiative transitions; $\gamma_{i}\left(\mathrm{~s}^{-1}\right)$ are upconversion rates; $\alpha_{i}\left(\mathrm{~s}^{-1}\right)$ are cross-relaxation rates.

Parameters $\alpha_{i}$ and $\gamma_{i}$ were varied to have the best fit with the experimental kinetics of green and red luminescence bands of $\mathrm{Er}^{3+}$ in $\beta-\mathrm{NaErF}_{4}$.

Seventeen different energy transfer processes were analysed in the developed rate equations, however, luminescence kinetics for both emissions could be modelled using seven of these processes shown in the Fig. 6 that were considered to be dominant in the investigated material. 


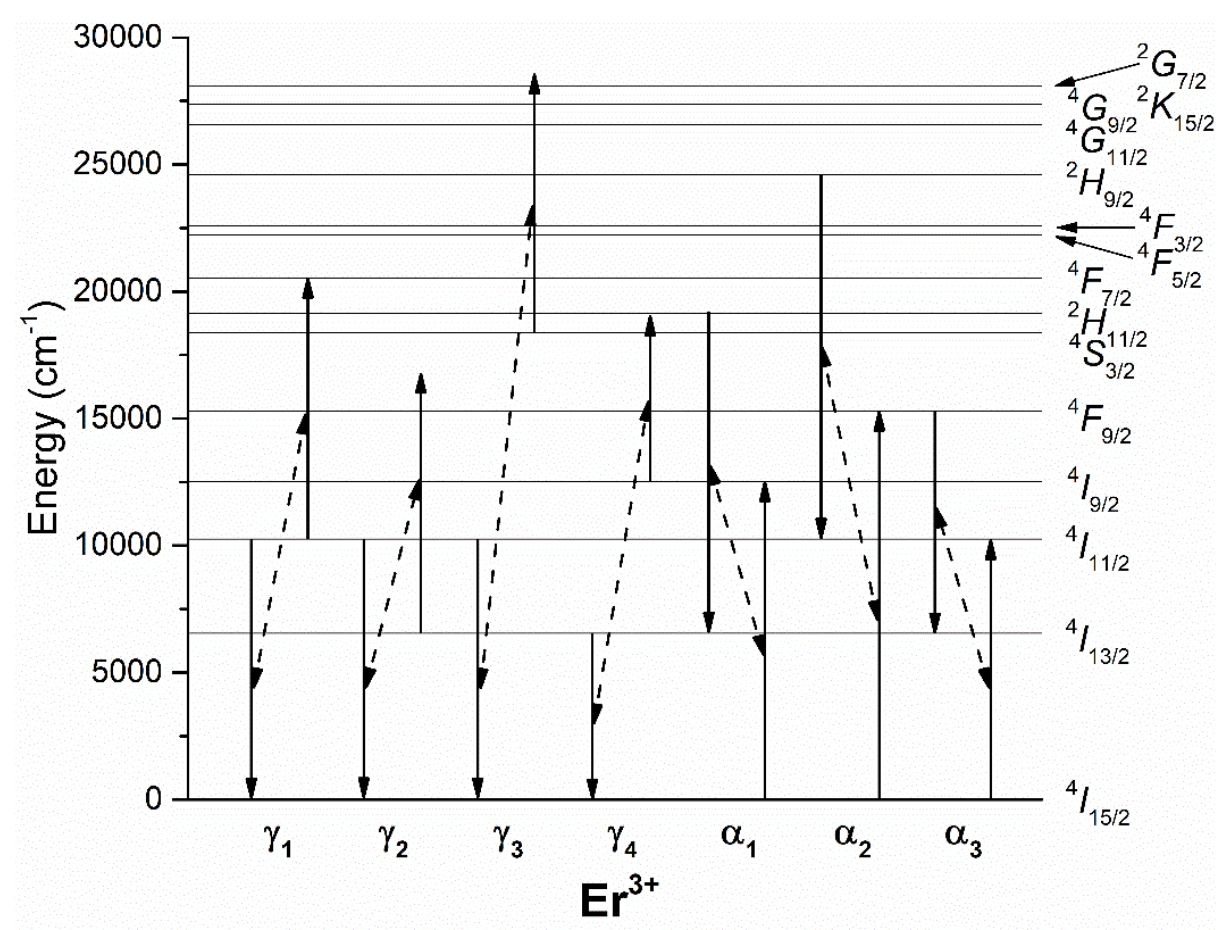

Fig. 6 Partial energy level diagram of $\mathrm{Er}^{3+}$ ions and the dominant energy transfer processes in $\beta-\mathrm{NaErF}_{4}$

The calculated kinetics were fitted well with experimental data with root-mean-square deviation of 0.051 for green emission and 0.062 for red emission. The experimental and calculated UCL kinetics of green and red emission excited in microcrystalline $\beta-\mathrm{NaErF}_{4}$ are shown in the Fig.7.
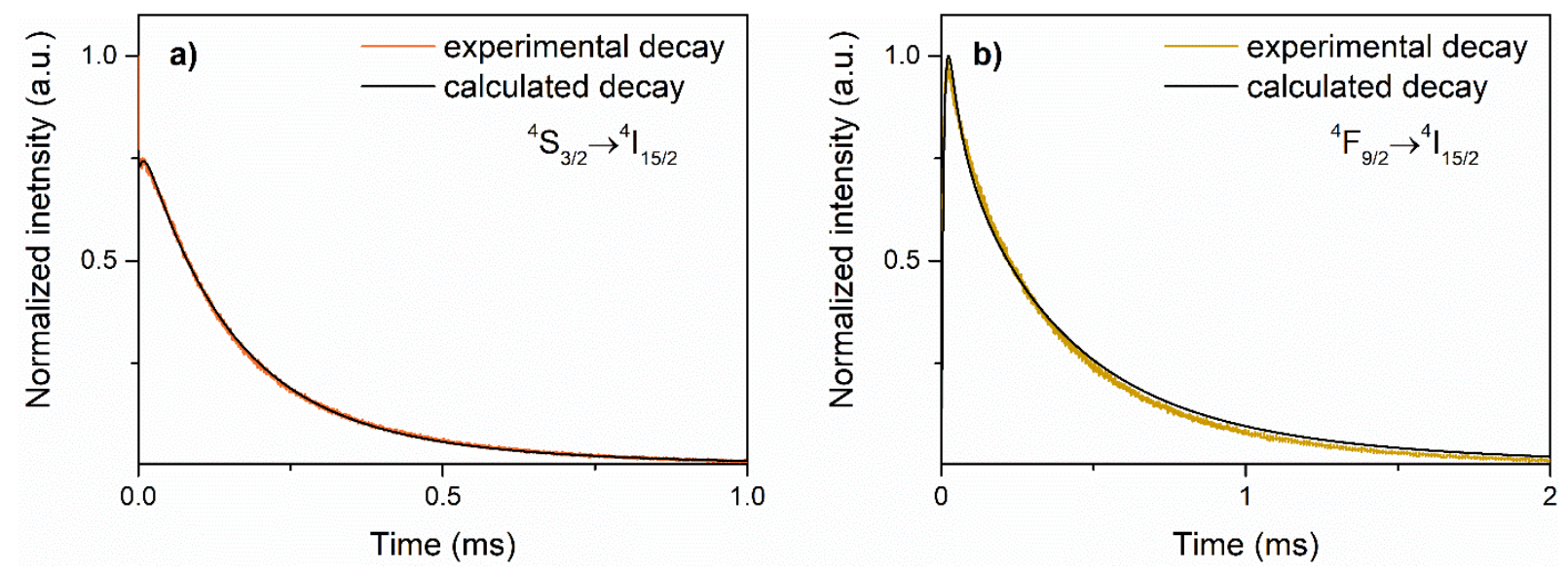

Fig. 7 Experimental and calculated UCL kinetics of a) green and b) red emission excited with $971 \mathrm{~nm}$ in microcrystalline $\beta-\mathrm{NaErF}_{4}$ 
The numerical values of mentioned dominant energy transfer rates are shown in the Table 1.

Table 1

Energy transfer rates in microcrystalline $\beta-\mathrm{NaErF}_{4}$

\begin{tabular}{cccc}
\hline & Upconversion & \multicolumn{2}{c}{ Cross-relaxation } \\
\hline Process & Upconversion rate $\left(\mathrm{s}^{-1}\right)$ & Process & Cross-relaxation rate $\left(\mathrm{s}^{-1}\right)$ \\
$\gamma_{1}$ & $(65.0 \pm 0.5) \cdot 10^{6}$ & $\alpha_{1}$ & $(1.00 \pm 0.03) \cdot 10^{4}$ \\
$\gamma_{2}$ & $(3.80 \pm 0.02) \cdot 10^{6}$ & $\alpha_{2}$ & $(4.0 \pm 0.1) \cdot 10^{4}$ \\
$\gamma_{3}$ & $(6.0 \pm 0.3) \cdot 10^{6}$ & $\alpha_{3}$ & $(7.5 \pm 0.5) \cdot 10^{4}$ \\
$\gamma_{4}$ & $(15 \pm 2) \cdot 10^{6}$ & & \\
\hline
\end{tabular}

The calculation of energy transfer rates offers quantitative information about the population dynamics of the emitting states. The results suggest that the green emission of $\mathrm{Er}^{3+}$ araised from upconversion processes $\gamma_{1}$ and $\gamma_{3}$ followed by a non-radiative decay to ${ }^{2} \mathrm{H}_{11 / 2}$ and ${ }^{4} \mathrm{~S}_{3 / 2}$ and $\gamma_{4}$ directly populated these states. From ${ }^{2} \mathrm{H}_{11 / 2}$ and ${ }^{4} \mathrm{~S}_{3 / 2} \mathrm{Er}^{3+}$ can decay radiatively resulting in green emission. The red emitting state can be populated by non-radiative multiphonon relaxation from ${ }^{4} \mathrm{~S}_{3 / 2}$ with decay rate of $1600 \mathrm{~s}^{-1}$ or it can be also populated by energy transfer processes $\gamma_{2}$ and $\alpha_{2}$. The contribution to the population of red emitting state from multiphonon relaxation is negligible, because the rate of this process is several orders of magnitude lower in comparison to upconversion and cross-relaxation. The energy transfer rates are considerably higher in comparison to values reported in similar $\mathrm{Er}^{3+}$ doped fluorides [33] suggesting highly efficient energy transfer processes of $\mathrm{Er}^{3+}$ ions $\beta-\mathrm{NaErF}_{4}$.

\section{Time-resolved site selective spectroscopy analysis}

The local environment of $\mathrm{Er}^{3+}$ ions was analysed using time-resolved site-selective spectroscopy. At $10 \mathrm{~K}$ temperature $\mathrm{Er}^{3+}$ ions in different local environment can be selectively excited. 


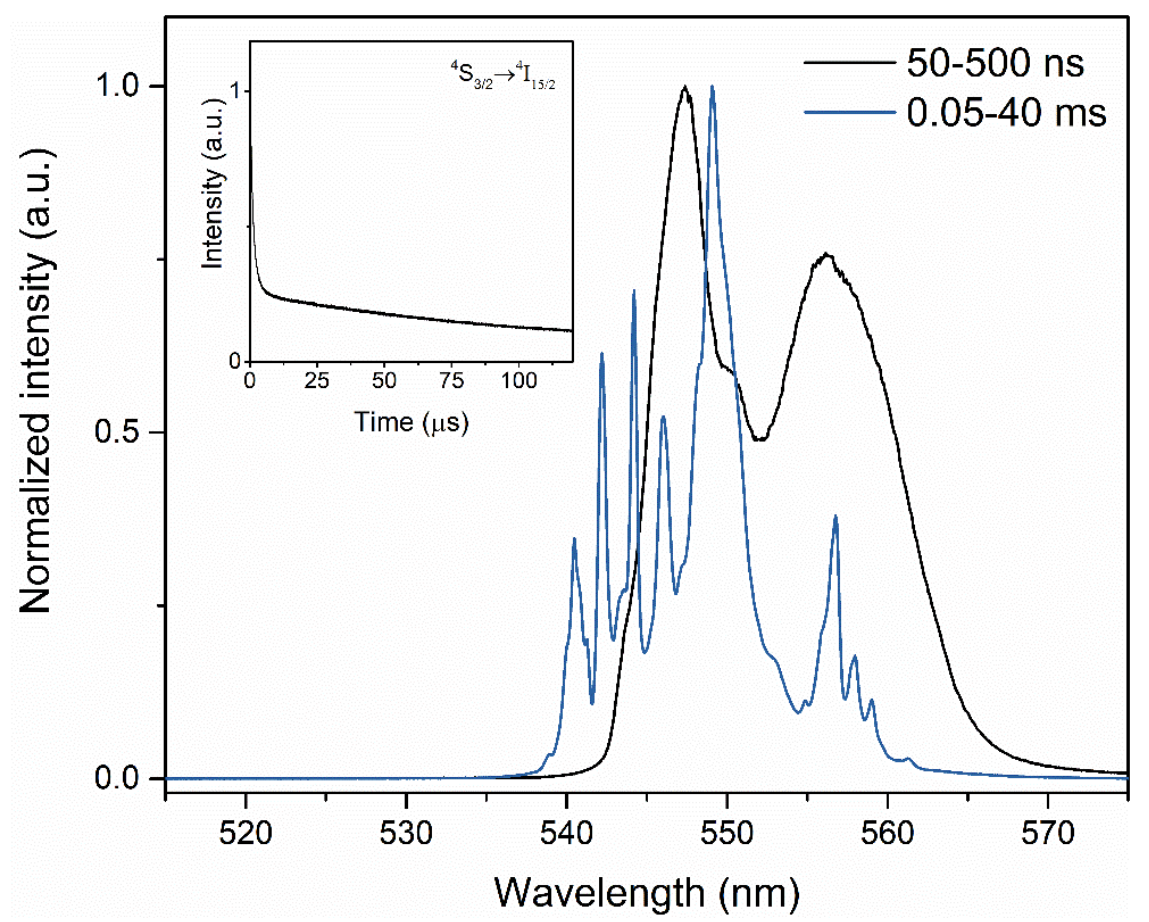

Fig. 8 Luminescence spectra of glass ceramics excited with $482 \mathrm{~nm}$, detected at 10K Inset: luminescence kinetics of green emission $\left({ }^{4} \mathrm{~S}_{3 / 2} \rightarrow{ }^{4} \mathrm{I}_{15 / 2}\right)$ excited with $482 \mathrm{~nm}$, detected at $10 \mathrm{~K}$

The luminescence kinetics of the green emission (see the inset of Fig. 8) revealed two processes characterized with fast and slow decay respectively. Luminescence spectra detected at 50-500 ns (fast decay) showed broad features characteristic to $\mathrm{Er}^{3+}$ ions in the amorphous environment. The relatively high phonon energy of the glass matrix enabled fast multiphonon relaxation resulting in rapid luminescence decay. At $0.05-40 \mathrm{~ms}$ (slow decay) narrow bands characteristic to $\mathrm{Er}^{3+}$ ions in crystalline environment was observed, indicating the incorporation of $\mathrm{Er}^{3+}$ ions in the low-phonon environment of $\beta-\mathrm{NaErF}_{4}$. The results suggest that $\mathrm{Er}^{3+}$ ions were located both in crystalline and glassy phases. 


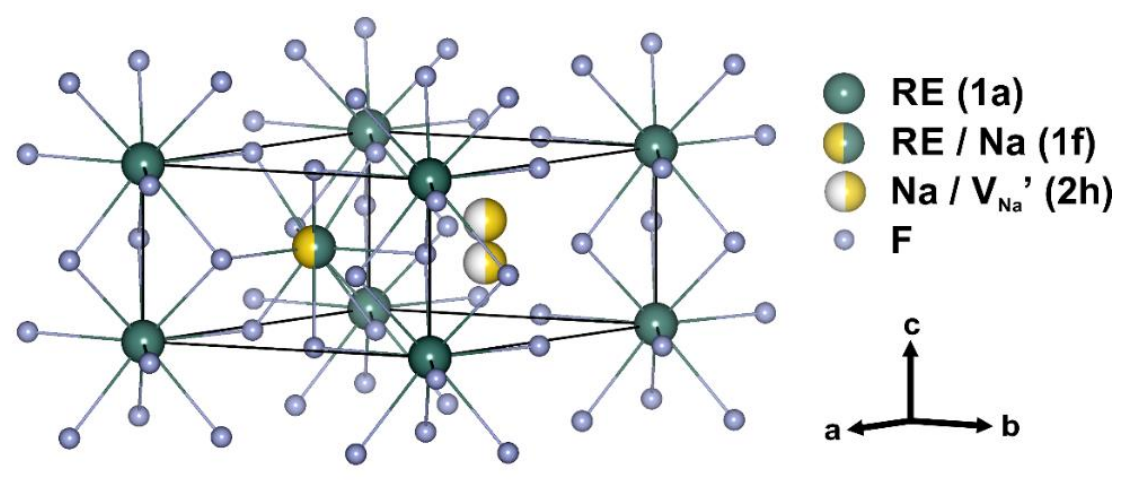

Fig. 9 Crystal structure of hexagonal $\mathrm{NaREF}_{4}$, atomic positions taken from Ref. [38] In $\beta-\mathrm{NaREF}_{4}$ there are three different cationic sites (see Fig. 9). Two of them are nine-fold coordinated with $\mathrm{F}^{-}$. One is solely occupied by $\mathrm{RE}^{3+}$ ions (1a) and the other is occupied by $\mathrm{RE}^{3+}$ and $\mathrm{Na}^{+}$that are distributed in alternating $\mathrm{Na}^{+}$and $\mathrm{RE}^{3+}$ layers along $\mathrm{z}$ axis (1f). The third cationic site is six-fold coordinated and occupied by $\mathrm{Na}^{+}$ions and vacancies (2h) [39].

Due to formation of multiple $\mathrm{RE}^{3+}$ sites in the crystalline lattice, several distinct luminescence spectra corresponding to $\mathrm{Er}^{3+}$ ions in different local environment have been detected in $\beta$ $\mathrm{NaREF}_{4}$ when the excitation wavelength was varied [39-41]. However, in the investigated glass ceramics no changes in the luminescence spectra of the $\mathrm{Er}^{3+}$ ions in the $\beta-\mathrm{NaErF}_{4}$ nanocrystals could be detected. Due to small distances between the neighbouring $\mathrm{Er}^{3+}$ ions, efficient energy transfer between different $\mathrm{Er}^{3+}$ sites is expected in $\beta-\mathrm{NaErF}_{4}$. Therefore, the different $\mathrm{Er}^{3+}$ positions can be distinguished only in a time interval faster than the energy transfer rate between the $\mathrm{Er}^{3+}$ ions. Unfortunately, in glass ceramics the rapid luminescence decay of $\mathrm{Er}^{3+}$ ions in the glass matrix overlapped with the luminescence from the crystalline phase, which prevented the identification of the different $\mathrm{Er}^{3+}$ sites and the detection of the energy transfer between them.

To detect several distinct $\mathrm{Er}^{3+}$ sites in $\beta-\mathrm{NaErF}_{4}$ and observe the energy transfer between them, microcrystalline single-phase $\beta-\mathrm{NaErF}_{4}$ was analysed. The luminescence kinetics of the microcrystalline $\beta-\mathrm{NaErF}_{4}$ excited with $484.4 \mathrm{~nm}$ is shown in the Fig. 10. 


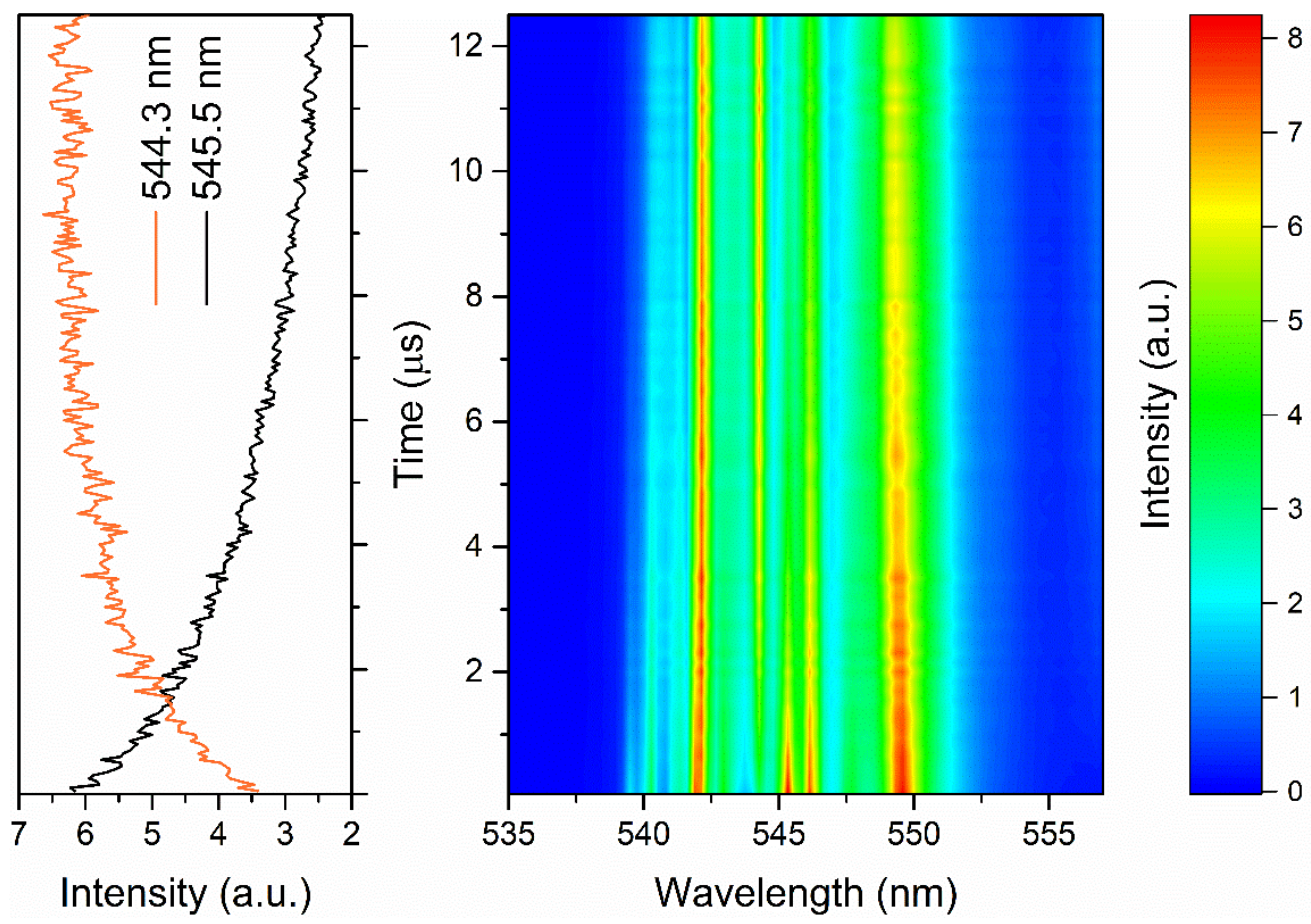

Fig. 10 Luminescence kinetics of the microcrystalline $\beta-\mathrm{NaErF}_{4}: \mathrm{Er}^{3+}$ detected at $10 \mathrm{~K}$ excited with $484.4 \mathrm{~nm}$

Exponential decay was observed for the most intense luminescence bands of $\mathrm{Er}^{3+}$ site excited with $484.4 \mathrm{~nm}$. The rise of intensity of several additional luminescence bands after the irradiation indicated energy transfer between different $\mathrm{Er}^{3+}$ sites. No deviations in the luminescence spectra resulting from all $\mathrm{Er}^{3+}$ sites could be observed after few $\mu$ s. The results indicated that different $\mathrm{Er}^{3+}$ sites can be selectively detected only shortly after a laser impulse excitation. Therefore, site-selective luminescence spectra were measured from 50 to $150 \mathrm{~ns}$ after the laser impulse. 


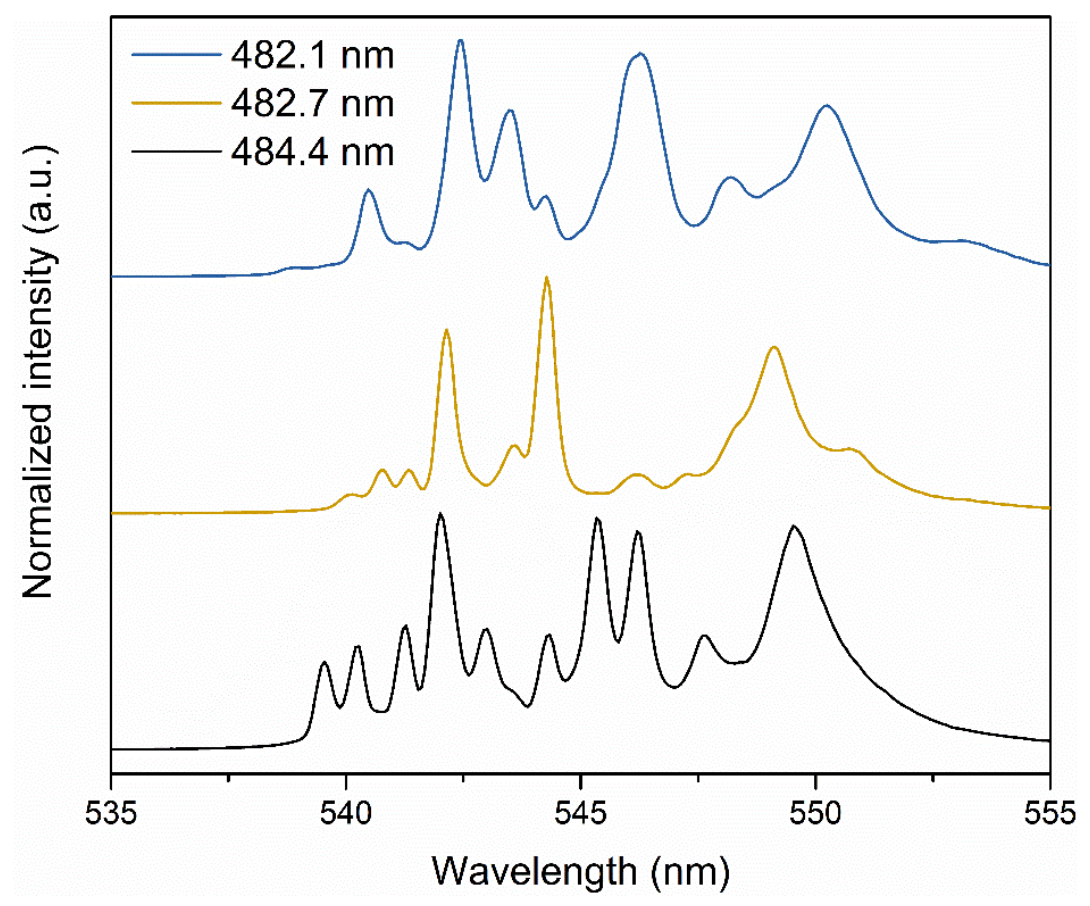

Fig. 11 Luminescence spectra of $\beta-\mathrm{NaErF}_{4}$ detected at $10 \mathrm{~K}, 50-150 \mathrm{~ns}$

Indeed, in the polycrystalline $\beta-\mathrm{NaErF}_{4}$ changes in the luminescence spectra detected at 50$150 \mathrm{~ns}$ could be observed when the excitation wavelength was varied, confirming the $\mathrm{Er}^{3+}$ multisite formation in these crystals (see Fig. 11). As mentioned previously, in the crystalline structure of $\beta-\mathrm{NaErF}_{4}$ (see Fig. 9) there are two distinct cationic positions, which contain $\mathrm{RE}^{3+}$ ions. Unexpectedly, three distinct luminescence spectra were detected indicating the incorporation of $\mathrm{Er}^{3+}$ ions in three distinct cationic sites. Similar results have been reported for $\mathrm{NaLaF}_{4}: \mathrm{Er}^{3+}[41], \beta-\mathrm{NaEuF}_{4}$ [40], $\beta-\mathrm{NaYF}_{4}: \operatorname{Pr}^{3+}[42]$ and $\beta-\mathrm{NaYF}_{4}: \mathrm{Er}^{3+}[43]$. The third unequivalent cationic position is assumed to be associated with the incorporation of $\mathrm{RE}^{3+}$ ions in the $\mathrm{Na}^{+}$position (2h) [40-43], however such replacement would result in the distortion of the crystalline structure and changes in the stoichiometry. Therefore, it is reasonable to assume that this replacement would not be efficient in highly doped materials such as $\beta-\mathrm{NaErF}_{4}$. In addition, the excitation efficiency and the luminescence intensity is similar for all three distinct $\mathrm{Er}^{3+}$ positions in the investigated microcrystalline $\beta-\mathrm{NaErF}_{4}$, suggesting a different origin of the third $\mathrm{Er}^{3+}$ position. We propose that the distortion in the local environment of one of the $\mathrm{Er}^{3+}$ positions (1a or 1f) in the crystalline lattice which could be created by the random occupation of $2 \mathrm{~h}$ positions filled with $\mathrm{Na}^{+}$ions and vacancies. However, to support this 
hypothesis, a detailed structural and spectroscopic analysis of $\beta-\mathrm{NaErF}_{4}$ single crystal is required.

It should be noted that the three distinct luminescence spectra detected in $\beta-\mathrm{NaErF}_{4}$ were identical to $\mathrm{Er}^{3+}$ doped $\beta-\mathrm{NaYF}_{4}$ reported previously [43], therefore we assume that the origin of the third $\mathrm{RE}^{3+}$ position in other $\beta-\mathrm{NaREF}_{4}$ materials is the same as for a $\beta-\mathrm{NaErF}_{4}$ investigated in the present study.

\section{Conclusions}

Novel transparent oxyfluoride glass ceramics containing single phase $\beta-\mathrm{NaErF}_{4}$ nanocrystals have been prepared for the first time. Splitting of UCL bands and abrupt increase of their intensities indicated that $\mathrm{Er}^{3+}$ ions partially incorporate the crystalline phase of the nanocomposite. Seven dominant energy transfer processes were identified in the $\beta-\mathrm{NaErF}_{4}$ crystalline phase. Rapid luminescence decay of erbium ions in the glass matrix hindered the identification of different activator sites of the glass ceramics.

Three distinct UCL signals could be selectively excited in polycrystalline $\beta-\mathrm{NaErF}_{4}$. This observation implies that the currently accepted assignment of the third $\mathrm{RE}^{3+}$ position to $\mathrm{Na}^{+} /$vacancy (2h) lattice site of $\beta-\mathrm{NaREF}_{4}$ is unlikely because in the case of $\beta-\mathrm{NaErF}_{4}$ the stoichiometry would be distorted. We suggest that the third $\mathrm{Er}^{3+}$ site originates from crystal field variations at the erbium ion positions (1a or 1f), which could be caused by the alternating occupation of the $2 \mathrm{~h}$ position by $\mathrm{Na}^{+}$ions and vacancies.

\section{Acknowledgments}

The authors wish to express gratitude to K. Smits for TEM measurements.

This research is funded by the Latvian Council of Science, project "Novel transparent nanocomposite oxyfluoride materials for optical applications”, project No. LZP-2018/1-0335. GK wishes to expresses gratitude to Arnis Riekstins "MikroTik" donation. Donations are administered by the University of Latvia Foundation. 


\section{References}

[1] F. Auzel, Upconversion and Anti-Stokes Processes with f and d Ions in Solids, Chem. Rev. 104 (2004) 139-174. doi:10.1021/cr020357g.

[2] J.C. Goldschmidt, S. Fischer, Upconversion for Photovoltaics - a Review of Materials, Devices and Concepts for Performance Enhancement, Adv. Opt. Mater. 3 (2015) 510535. doi:10.1002/adom.201500024.

[3] J. Shen, L. Zhao, G. Han, Lanthanide-doped upconverting luminescent nanoparticle platforms for optical imaging-guided drug delivery and therapy, Adv. Drug Deliv. Rev. 65 (2013) 744-755. doi:10.1016/j.addr.2012.05.007.

[4] Z. Gu, L. Yan, G. Tian, S. Li, Z. Chai, Y. Zhao, Recent Advances in Design and Fabrication of Upconversion Nanoparticles and Their Safe Theranostic Applications, Adv. Mater. 25 (2013) 3758-3779. doi:10.1002/adma.201301197.

[5] J. Zhou, Z. Liu, F. Li, Upconversion nanophosphors for small-animal imaging, Chem. Soc. Rev. 41 (2012) 1323-1349. doi:10.1039/C1CS15187H.

[6] L. Li, Y. Yang, R. Fan, S. Chen, P. Wang, B. Yang, W. Cao, Conductive Upconversion Er,Yb-FTO Nanoparticle Coating To Replace Pt as a Low-Cost and High-Performance Counter Electrode for Dye-Sensitized Solar Cells, ACS Appl. Mater. Interfaces. 6 (2014) 8223-8229. doi:10.1021/am5009776.

[7] H. Scheife, G. Huber, E. Heumann, S. Bär, E. Osiac, Advances in up-conversion lasers based on $\mathrm{Er}^{3+}$ and $\mathrm{Pr}^{3+}$, Opt. Mater. (Amst). 26 (2004) 365-374.

doi:10.1016/j.optmat.2003.10.010.

[8] M. Wang, G. Abbineni, A. Clevenger, C. Mao, S. Xu, Upconversion nanoparticles: synthesis, surface modification and biological applications, Nanomedicine Nanotechnology, Biol. Med. 7 (2011) 710-729. doi:10.1016/j.nano.2011.02.013.

[9] A. Shalav, B.S. Richards, M.A. Green, Luminescent layers for enhanced silicon solar cell performance: Up-conversion, Sol. Energy Mater. Sol. Cells. 91 (2007) 829-842. doi:10.1016/j.solmat.2007.02.007. 
[10] A. Sarakovskis, J. Grube, A. Mishnev, M. Springis, Up-conversion processes in $\mathrm{NaLaF}_{4}: \mathrm{Er}^{3+}$, Opt. Mater. (Amst). 31 (2009) 1517-1524.

doi:10.1016/j.optmat.2009.02.015.

[11] C. Renero-Lecuna, R. Martín-Rodríguez, R. Valiente, J. González, F. Rodríguez, K.W. Krämer, H.U. Güdel, Origin of the High Upconversion Green Luminescence Efficiency in $\beta-\mathrm{NaYF}_{4}: 2 \% \mathrm{Er}^{3+}, 20 \% \mathrm{Yb}^{3+}$, Chem. Mater. 23 (2011) 3442-3448. doi:10.1021/cm2004227.

[12] F. Shi, J. Wang, X. Zhai, D. Zhao, W. Qin, Facile synthesis of $\beta-\mathrm{NaLuF}_{4}: \mathrm{Yb} / \mathrm{Tm}$ hexagonal nanoplates with intense ultraviolet upconversion luminescence, CrystEngComm. 13 (2011) 3782-3787. doi:10.1039/c1ce05092c.

[13] F. Wang, X. Liu, Recent advances in the chemistry of lanthanide-doped upconversion nanocrystals, Chem. Soc. Rev. 38 (2009) 976. doi:10.1039/b809132n.

[14] G. Liu, Advances in the theoretical understanding of photon upconversion in rare-earth activated nanophosphors, Chem. Soc. Rev. 44 (2015) 1635-1652. doi:10.1039/C4CS00187G.

[15] J.L. Sommerdijk, Influence of host lattice on the infrared-excited visible luminescence in $\mathrm{Yb}^{3+}, \mathrm{Er}^{3+}$-doped fluorides, J. Lumin. 6 (1973) 61-67. doi:10.1016/00222313(73)90095-1.

[16] P.P. Fedorov, A.A. Luginina, A.I. Popov, Transparent oxyfluoride glass ceramics, J. Fluor. Chem. 172 (2015) 22-50. doi:10.1016/j.jfluchem.2015.01.009.

[17] A. de Pablos-Martín, G.C. Mather, F. Muñoz, S. Bhattacharyya, T. Höche, J.R. Jinschek, T. Heil, A. Durán, M.J. Pascual, Design of oxy-fluoride glass-ceramics containing $\mathrm{NaLaF}_{4}$ nano-crystals, J. Non. Cryst. Solids. 356 (2010) 3071-3079. doi:10.1016/j.jnoncrysol.2010.04.057.

[18] M. Środa, Effect of $\mathrm{Er}_{2} \mathrm{O}_{3}$ on thermal stability of oxyfluoride glass, J. Therm. Anal. Calorim. 97 (2009) 239-243. doi:10.1007/s10973-009-0257-3.

[19] F. Xin, S. Zhao, L. Huang, D. Deng, G. Jia, H. Wang, S. Xu, Up-conversion luminescence of $\mathrm{Er}^{3+}$-doped glass ceramics containing $\beta-\mathrm{NaGdF}_{4}$ nanocrystals for 
silicon solar cells, Mater. Lett. 78 (2012) 75-77. doi:10.1016/j.matlet.2012.03.037.

[20] A. Herrmann, M. Tylkowski, C. Bocker, C. Rüssel, Cubic and Hexagonal $\mathrm{NaGdF}_{4}$ Crystals Precipitated from an Aluminosilicate Glass: Preparation and Luminescence Properties, Chem. Mater. 25 (2013) 2878-2884. doi:10.1021/cm401454y.

[21] A. Sarakovskis, G. Krieke, Upconversion luminescence in erbium doped transparent oxyfluoride glass ceramics containing hexagonal $\mathrm{NaYF}_{4}$ nanocrystals, J. Eur. Ceram. Soc. 35 (2015) 3665-3671. doi:10.1016/j.jeurceramsoc.2015.06.014.

[22] Y. Gao, Y. Hu, P. Ren, D. Zhou, J. Qiu, Phase transformation and enhancement of luminescence in the $\mathrm{Tb}^{3+}-\mathrm{Yb}^{3+}$ co-doped oxyfluoride glass ceramics containing $\mathrm{NaYF}_{4}$ nanocrystals, J. Eur. Ceram. Soc. 36 (2016) 2825-2830. doi:10.1016/j.jeurceramsoc.2016.04.027.

[23] H. Wang, Z. Yi, L. Rao, H. Liu, S. Zeng, High quality multi-functional $\mathrm{NaErF}_{4}$ nanocrystals: structure-controlled synthesis, phase-induced multi-color emissions and tunable magnetic properties, J. Mater. Chem. C. 1 (2013) 5520-5526. doi:10.1039/c3tc30796d.

[24] H. Wang, W. Lu, T. Zeng, Z. Yi, L. Rao, H. Liu, S. Zeng, Multi-functional NaErF $: Y b$ nanorods: Enhanced red upconversion emission, in vitro cell, in vivo X-ray, and T2weighted magnetic resonance imaging, Nanoscale. 6 (2014) 2855-2860. doi:10.1039/c3nr05782h.

[25] H. Wang, W. Lu, Z. Yi, L. Rao, S. Zeng, Z. Li, Enhanced upconversion luminescence and single-band red emission of $\mathrm{NaErF}_{4}$ nanocrystals via $\mathrm{Mn}^{2+}$ doping, J. Alloys Compd. 618 (2015) 776-780. doi:10.1016/j.jallcom.2014.08.174.

[26] W. Xie, X. An, L. Chen, J. Li, J. Leng, W. Lü, L. Zhang, Y. Luo, Tunable phase and upconverting luminescence of $\mathrm{Gd}^{3+}$ co-doped $\mathrm{NaErF}_{4}: \mathrm{Yb}^{3+}$ nanostructures, Mater. Res. Bull. 95 (2017) 509-514. doi:10.1016/j.materresbull.2017.08.033.

[27] J. Xu, D. Yang, W. Han, S. Dong, T. Jia, F. He, H. Bi, S. Gai, L. Li, P. Yang, A novel strategy for markedly enhancing the red upconversion emission in $\mathrm{Er}^{3+} / \mathrm{Tm}^{3+}$ cooperated nanoparticles, J. Mater. Chem. C. 6 (2018) 7533-7540. doi:10.1039/C8TC02370K. 
[28] Y. Shang, S. Hao, W. Lv, T. Chen, L. Tian, Z. Lei, C. Yang, Confining excitation energy of $\mathrm{Er}^{3+}$-sensitized upconversion nanoparticles through introducing various energy trapping centers, J. Mater. Chem. C. 6 (2018) 3869-3875. doi:10.1039/C7TC05742C.

[29] Q. Chen, X. Xie, B. Huang, L. Liang, S. Han, Z. Yi, Y. Wang, Y. Li, D. Fan, L. Huang, $\mathrm{X}$. Liu, Confining Excitation Energy in $\mathrm{Er}^{3+}$-Sensitized Upconversion Nanocrystals through $\mathrm{Tm}^{3+}$-Mediated Transient Energy Trapping, Angew. Chemie Int. Ed. 56 (2017) 7605-7609. doi:10.1002/anie.201703012.

[30] X. Wang, A. Yakovliev, T.Y. Ohulchanskyy, L. Wu, S. Zeng, X. Han, J. Qu, G. Chen, Efficient Erbium-Sensitized Core/Shell Nanocrystals for Short Wave Infrared Bioimaging, Adv. Opt. Mater. 1800690 (2018) 1800690. doi:10.1002/adom.201800690.

[31] G. Krieke, A. Sarakovskis, M. Springis, Upconversion luminescence of a transparent glass ceramics with hexagonal $\mathrm{Na}(\mathrm{Gd}, \mathrm{Lu}) \mathrm{F}_{4}$ nanocrystals, J. Alloys Compd. 694 (2017) 952-958. doi:10.1016/j.jallcom.2016.10.156.

[32] A. de Pablos-Martín, A. Durán, M.J. Pascual, Nanocrystallisation in oxyfluoride systems: mechanisms of crystallisation and photonic properties, Int. Mater. Rev. 57 (2012) 165-186. doi:10.1179/1743280411Y.0000000004.

[33] A.M. Tkachuk, S.E. Ivanova, M.-F. Joubert, Y. Guyot, V.P. Gapontzev, Population of excited erbium levels in $\mathrm{Er}^{3+}: \mathrm{Na}_{0.4} \mathrm{Y}_{0.6} \mathrm{~F}_{2.2}$ (Er:NYF) laser crystals, J. Alloys Compd. 380 (2004) 130-135. doi:10.1016/j.jallcom.2004.03.038.

[34] A. Shyichuk, S.S. Câmara, I.T. Weber, A.N. Carneiro Neto, L.A.O. Nunes, S. Lis, R.L. Longo, O.L. Malta, Energy transfer upconversion dynamics in $\mathrm{YVO}_{4}: \mathrm{Yb}^{3+}, \mathrm{Er}^{3+}, \mathrm{J}$. Lumin. 170 (2016) 560-570. doi:10.1016/j.jlumin.2015.07.005.

[35] M. Rico, C. Zaldo, J. Massons, F. Díaz, Optical absorption of in and, J. Phys. Condens. Matter. 10 (1998) 10101-10113. doi:10.1088/0953-8984/10/44/015.

[36] G. Yao, C. Lin, Q. Meng, P. Stanley May, M.T. Berry, Calculation of Judd-Ofelt parameters for $\mathrm{Er}^{3+}$ in $\beta-\mathrm{NaYF}_{4}: \mathrm{Yb}^{3+}, \mathrm{Er}^{3+}$ from emission intensity ratios and diffuse reflectance spectra, J. Lumin. 160 (2015) 276-281. doi:10.1016/j.jlumin.2014.12.025. 
[37] S.É. Ivanova, A.M. Tkachuk, M.-F. Joubert, Y. Guiout, S. Gui, Spectroscopic Study of Neodymium-Doped Sodium-Yttrium Double Fluoride $\mathrm{Nd}^{3+}: \mathrm{Na}_{0.4} \mathrm{Y}_{0.6} \mathrm{~F}_{2.2}$ crystals, Opt. Spectrosc. 89 (2000) 535-548. doi:10.1134/BF03356018.

[38] A. Grzechnik, P. Bouvier, M. Mezouar, M.D. Mathews, A.K. Tyagi, J. Köhler, Hexagonal $\mathrm{Na}_{1.5} \mathrm{Y}_{1.5} \mathrm{~F}_{6}$ at High Pressures, J. Solid State Chem. 165 (2002) 159-164. doi:10.1006/jssc.2001.9525.

[39] A. Aebischer, M. Hostettler, J. Hauser, K. Krämer, T. Weber, H.U. Güdel, H.-B. Bürgi, Structural and Spectroscopic Characterization of Active Sites in a Family of LightEmitting Sodium Lanthanide Tetrafluorides, Angew. Chemie Int. Ed. 45 (2006) 28022806. doi:10.1002/anie.200503966.

[40] D. Zakaria, R. Mahiou, D. Avignant, M. Zahir, Single-crystal structure refinement and luminescence analysis of $\beta-\mathrm{NaEuF}_{4}, \mathrm{~J}$. Alloys Compd. 257 (1997) 65-68. doi:10.1016/S0925-8388(97)00016-9.

[41] A. Sarakovskis, G. Krieke, G. Doke, J. Grube, L. Grinberga, M. Springis, Comprehensive study on different crystal field environments in highly efficient $\mathrm{NaLaF}_{4}: \mathrm{Er}^{3+}$ upconversion phosphor, Opt. Mater. (Amst). 39 (2015) 90-96. doi:10.1016/j.optmat.2014.11.004.

[42] N. Martin, P. Boutinaud, M. Malinowski, R. Mahiou, J.. Cousseins, Optical spectra and analysis of $\mathrm{Pr}^{3+}$ in $\beta-\mathrm{NaYF}_{4}$, J. Alloys Compd. 275-277 (1998) 304-306. doi:10.1016/S0925-8388(98)00323-5.

[43] G. Krieke, A. Sarakovskis, Crystallization and upconversion luminescence of distorted fluorite nanocrystals in $\mathrm{Ba}^{2+}$ containing oxyfluoride glass ceramics, J. Eur. Ceram. Soc. 36 (2016) 1715-1722. doi:10.1016/j.jeurceramsoc.2016.01.025. 


\section{Figure captions}

Fig. 1. XRD patterns of precursor glass and glass ceramics heat treated at $600^{\circ} \mathrm{C}$ for $10 \mathrm{~h}$. Inset: photograph of glass and transparent glass ceramic samples

Fig. 2. a) and c) TEM micrographs, b) selected area electron diffraction pattern of glass ceramics heat treated at $600^{\circ} \mathrm{C}$ for $10 \mathrm{~h}$

Fig. 3. a) UCL spectra normalized for the green emission and b) UCL kinetics of the green emission of glass and glass ceramics excited with $971 \mathrm{~nm}$

Fig. 4. Partial energy level diagram of $\mathrm{Er}^{3+}$ ions; UCL excitation and experimentally observed radiative transitions

Fig. 5. UCL kinetics of the red emission excited with $971 \mathrm{~nm}$ in microcrystalline $\beta-\mathrm{NaErF}_{4}$ and glass ceramics

Fig. 6. Partial energy level diagram of $\mathrm{Er}^{3+}$ ions and the dominant energy transfer processes in $\beta-\mathrm{NaErF}_{4}$

Fig. 7. Experimental and calculated UCL kinetics of a) green and b) red emission excited with $971 \mathrm{~nm}$ in microcrystalline $\beta-\mathrm{NaErF}_{4}$

Fig. 8. Luminescence spectra of glass ceramics excited with $482 \mathrm{~nm}$, detected at $10 \mathrm{~K}$. Inset: luminescence kinetics of green emission $\left({ }^{4} \mathrm{~S}_{3 / 2} \rightarrow{ }^{4} \mathrm{I}_{15 / 2}\right)$ excited with $482 \mathrm{~nm}$, detected at $10 \mathrm{~K}$

Fig. 9. Crystal structure of hexagonal $\mathrm{NaREF}_{4}$, atomic positions taken from [39]

Fig. 10. Luminescence kinetics of the microcrystalline $\beta-\mathrm{NaErF}_{4}: \mathrm{Er}^{3+}$ detected at $10 \mathrm{~K}$ excited with $484.4 \mathrm{~nm}$

Fig. 11. Luminescence spectra of $\beta-\mathrm{NaErF}_{4}$ detected at $10 \mathrm{~K}, 50-150 \mathrm{~ns}$ 
- New transparent glass ceramics containing hexagonal $\mathrm{NaErF}_{4}$ were prepared.

- The formation of $\mathrm{NaErF}_{4}$ nanocrystals enhanced the upconversion luminescence.

- Dominant energy transfer mechanisms of erbium ions were identified.

- Three distinct erbium positions where detected in $\mathrm{NaErF}_{4}$ lattice.

- The origin of multisite formation in $\mathrm{NaErF} 4$ was discussed. 
Table 1

Energy transfer rates in microcrystalline $\beta-\mathrm{NaErF}_{4}$

\begin{tabular}{cccc}
\hline & Upconversion & & Cross-relaxation \\
\hline Process & Upconversion rate $\left(\mathrm{s}^{-1}\right)$ & Process & Cross-relaxation rate $\left(\mathrm{s}^{-1}\right)$ \\
$\gamma_{1}$ & $(65.0 \pm 0.5) \cdot 10^{6}$ & $\alpha_{1}$ & $(1.00 \pm 0.03) \cdot 10^{4}$ \\
$\gamma_{2}$ & $(3.80 \pm 0.02) \cdot 10^{6}$ & $\alpha_{2}$ & $(4.0 \pm 0.1) \cdot 10^{4}$ \\
$\gamma_{3}$ & $(6.0 \pm 0.3) \cdot 10^{6}$ & $\alpha_{3}$ & $(7.5 \pm 0.5) \cdot 10^{4}$ \\
$\gamma_{4}$ & $(15 \pm 2) \cdot 10^{6}$ & & \\
\hline
\end{tabular}




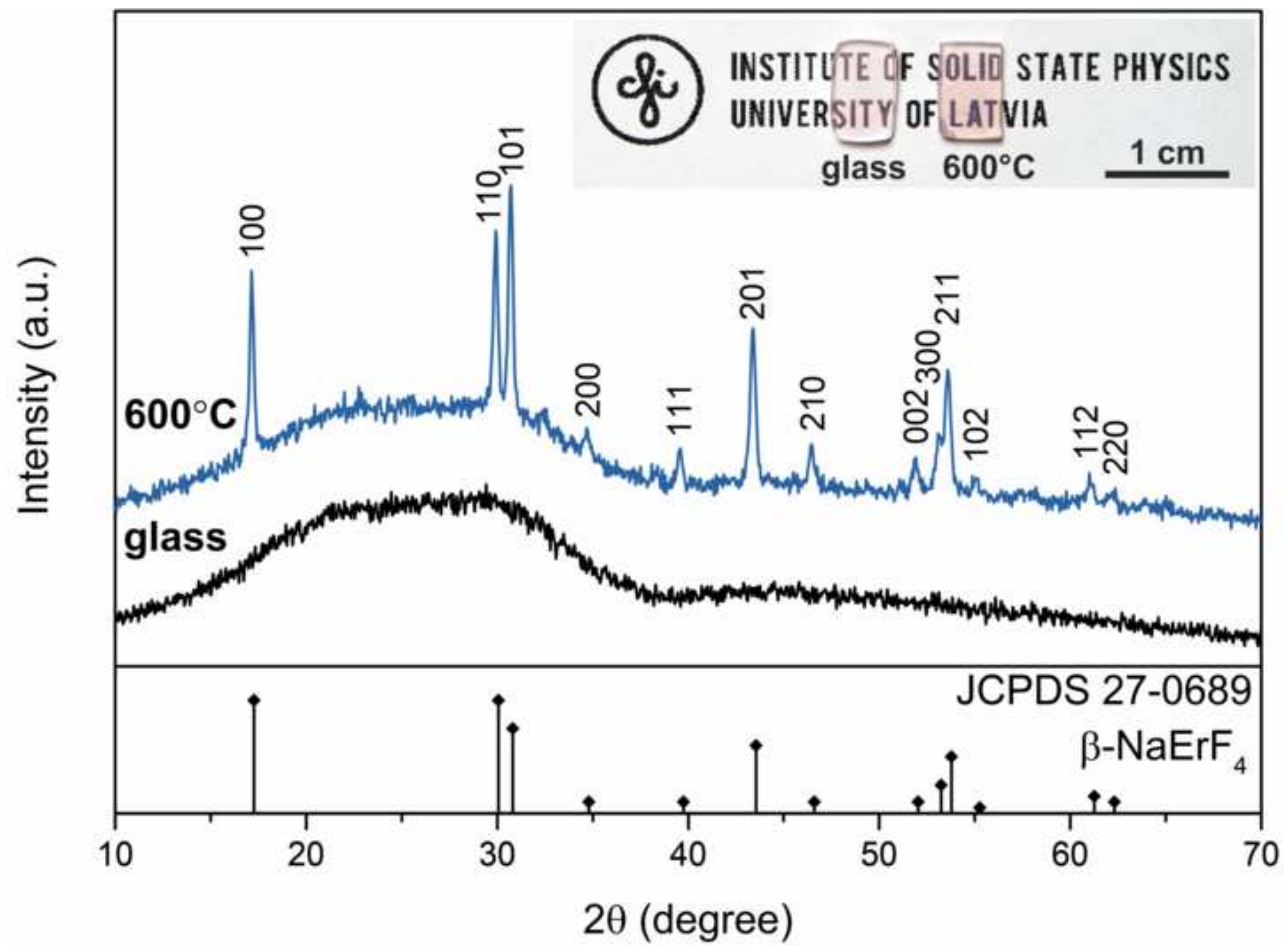


Click here to download high resolution image
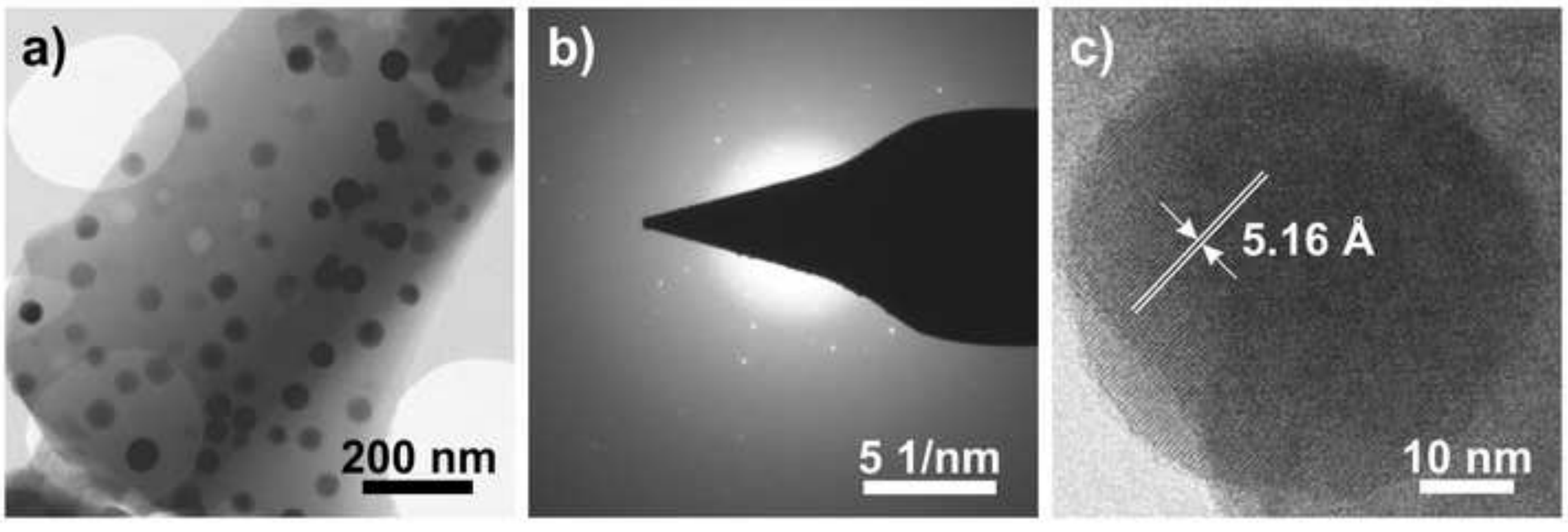

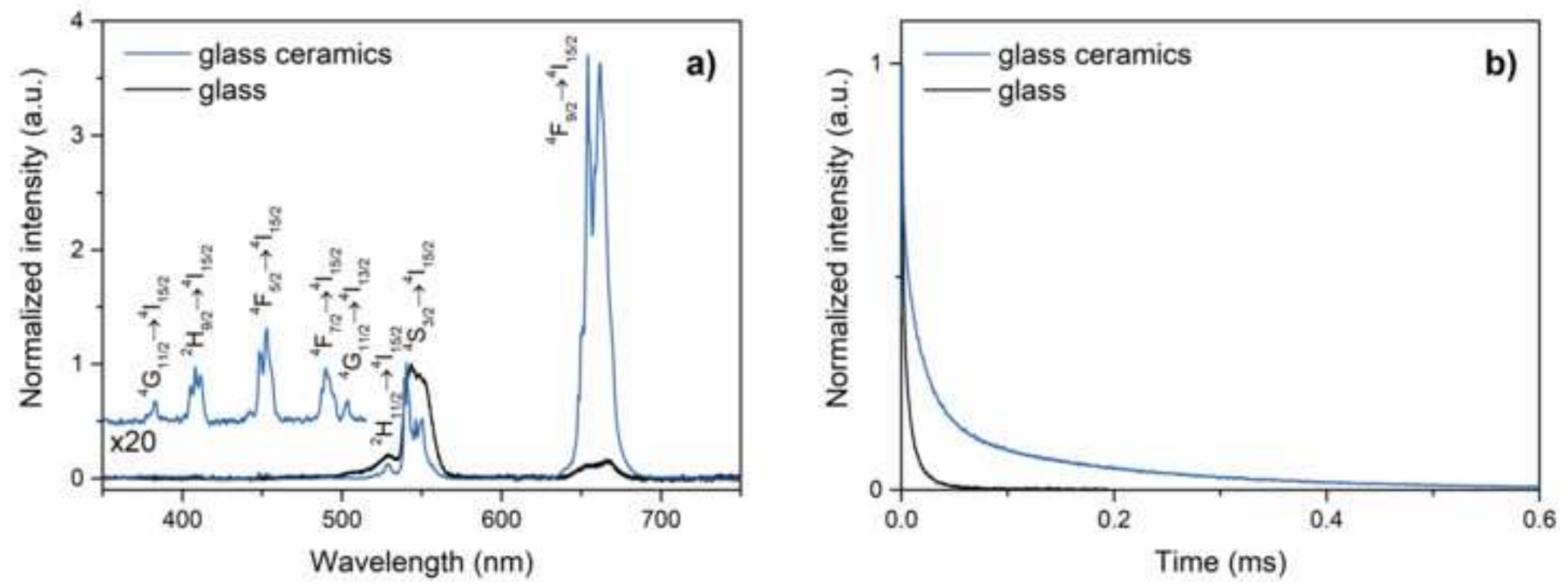


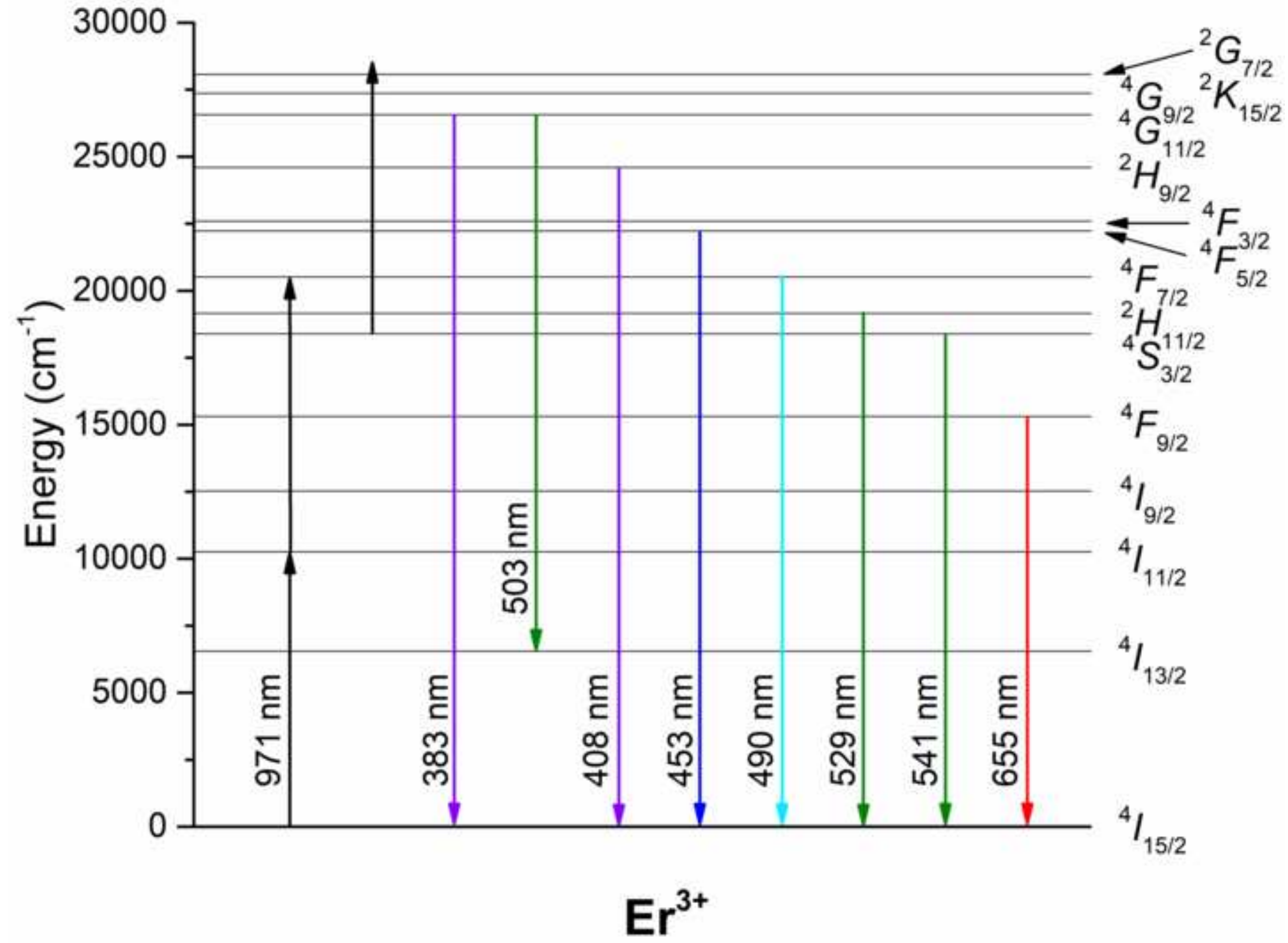




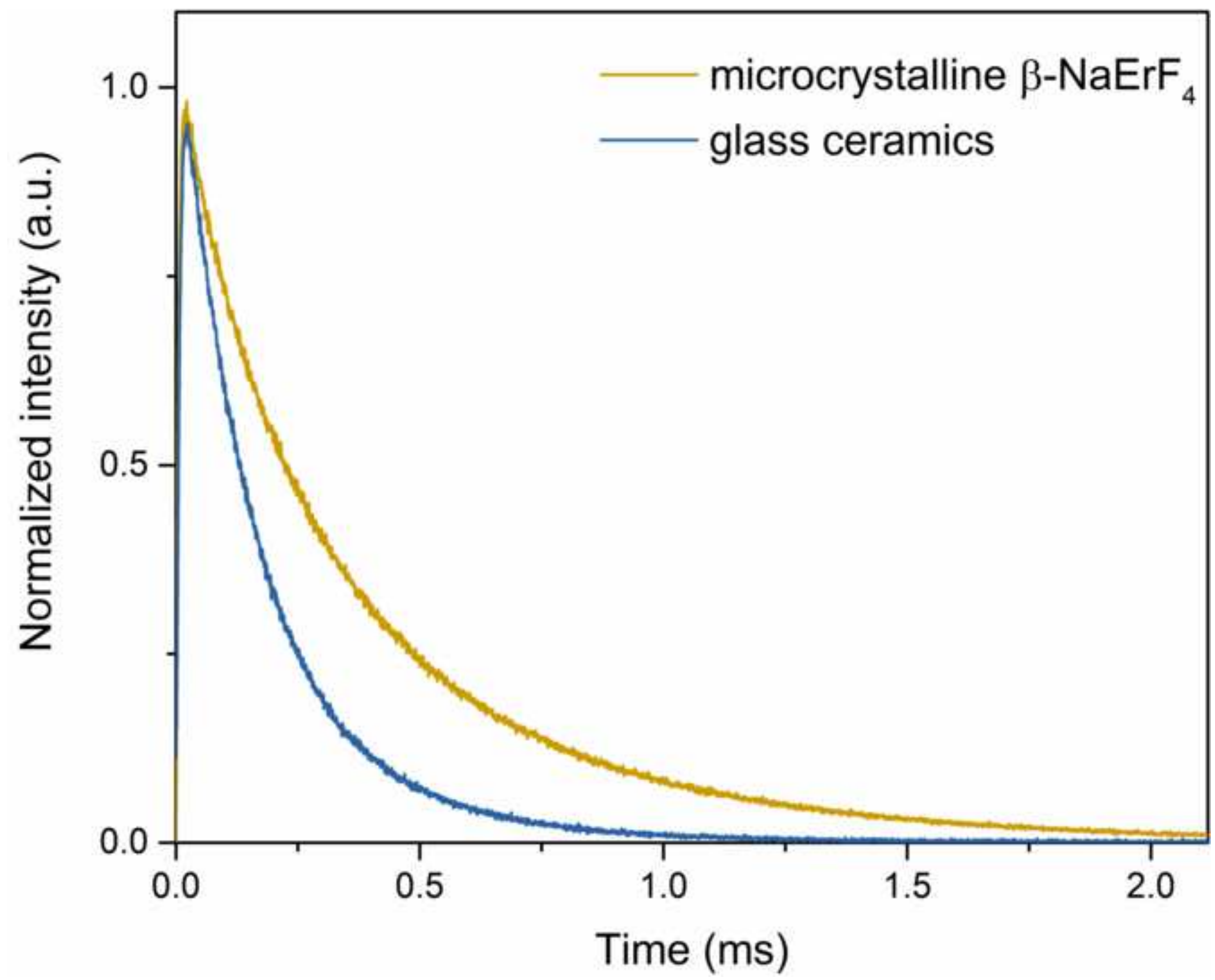



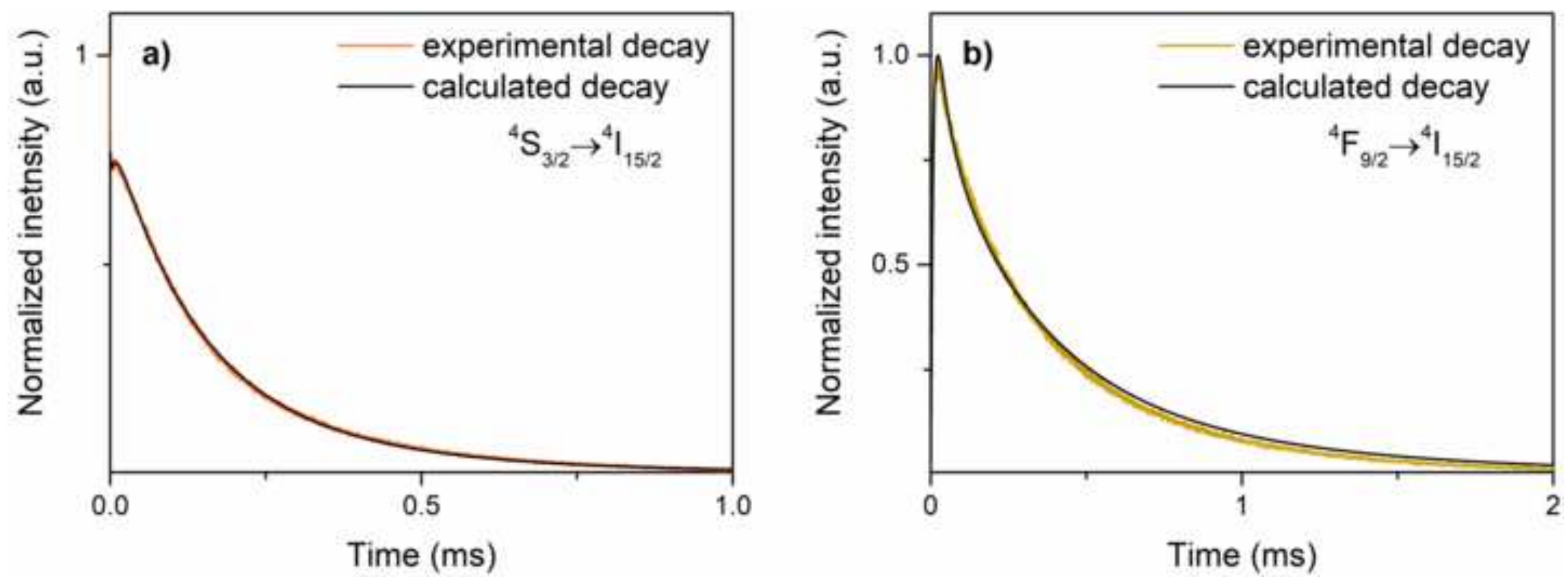


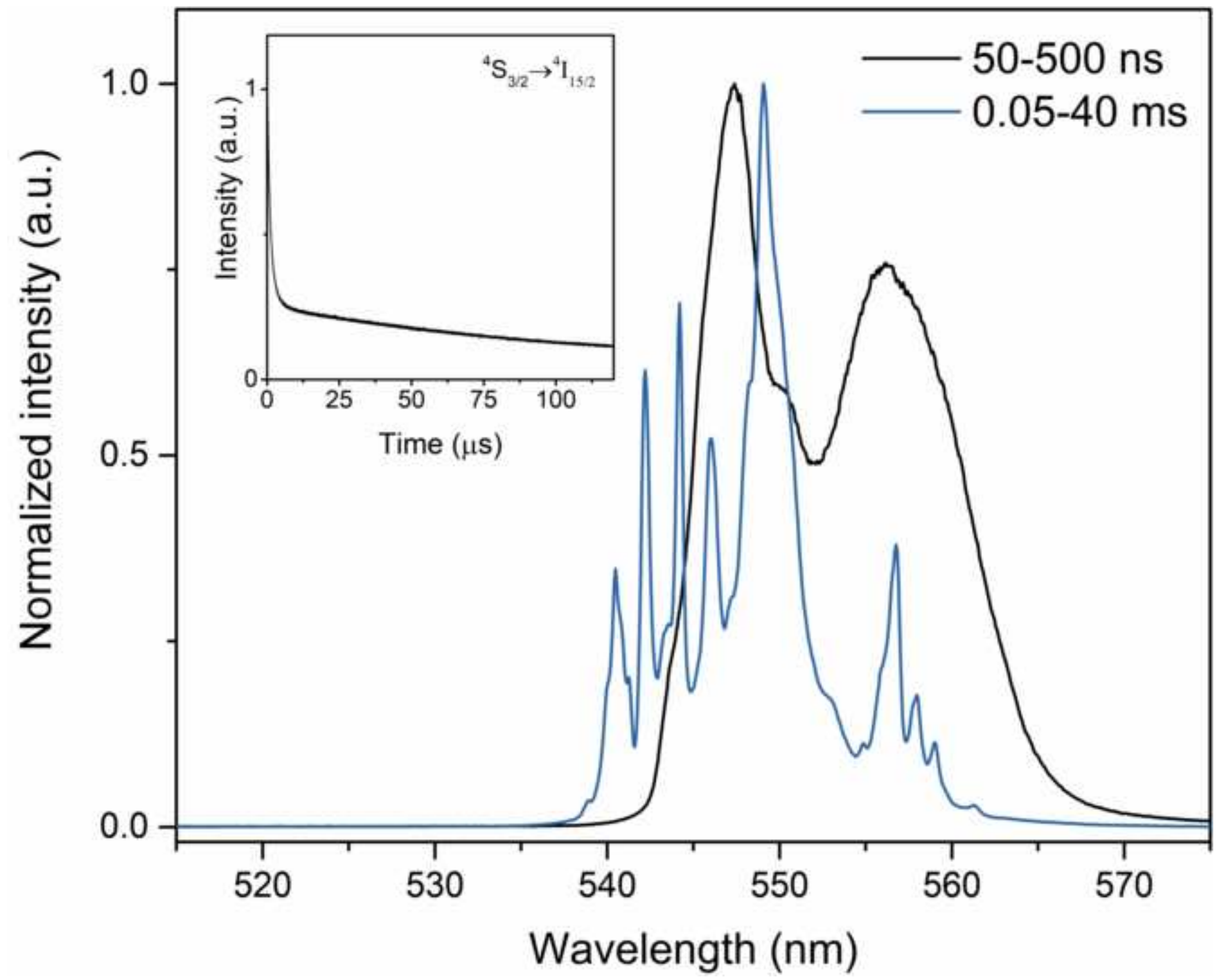




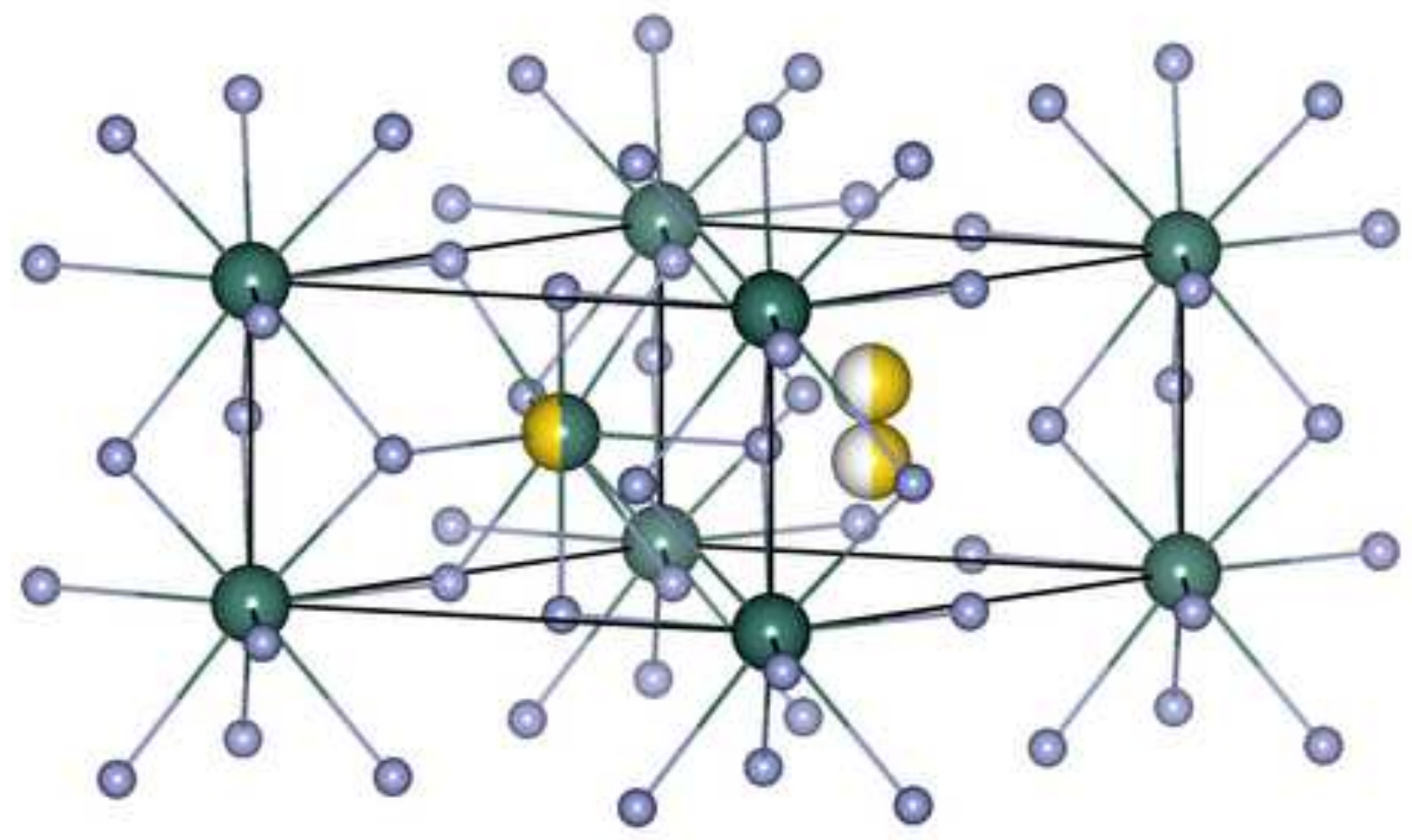

(-) RE (1a) (1) RE / Na (1f) $\mathrm{Na} / \mathrm{V}_{\mathrm{Na}}{ }^{\prime}(2 \mathrm{~h})$ - $\mathbf{F}$

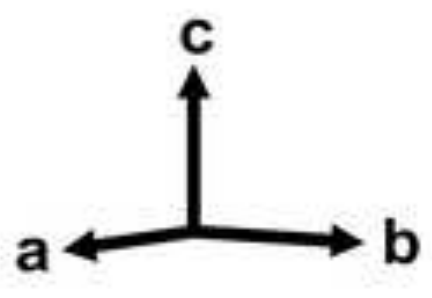




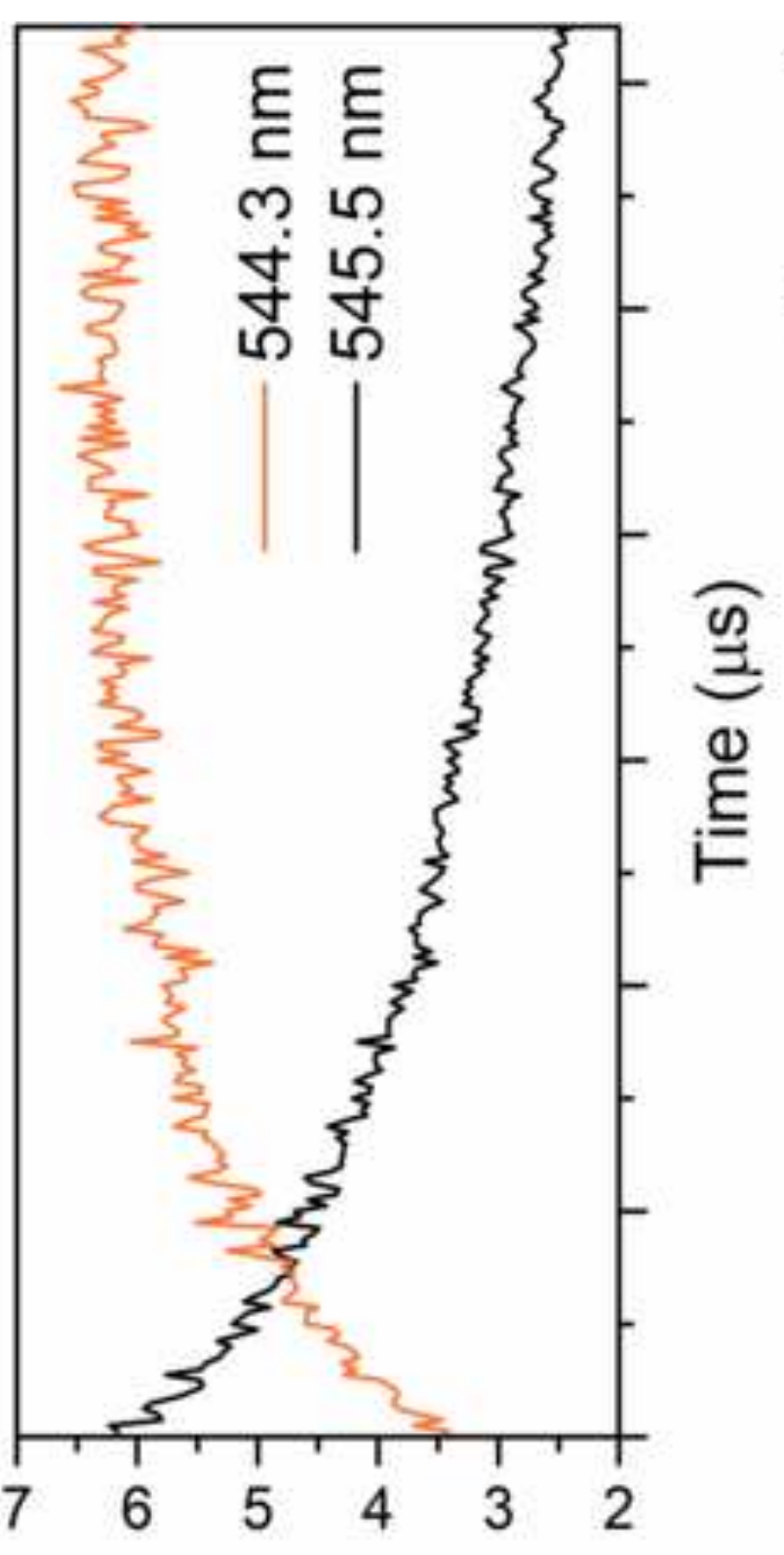

Intensity (a.u.)
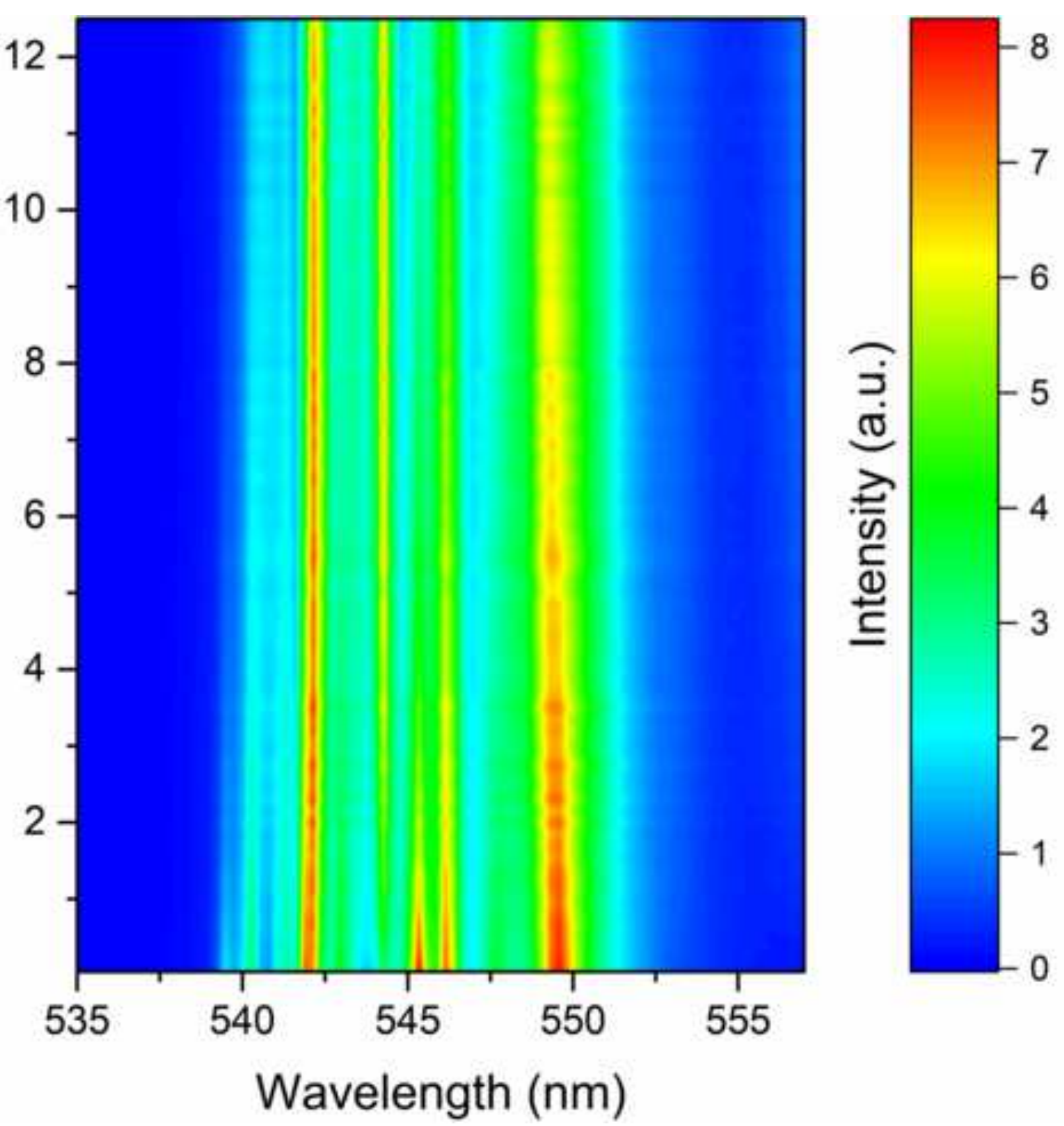


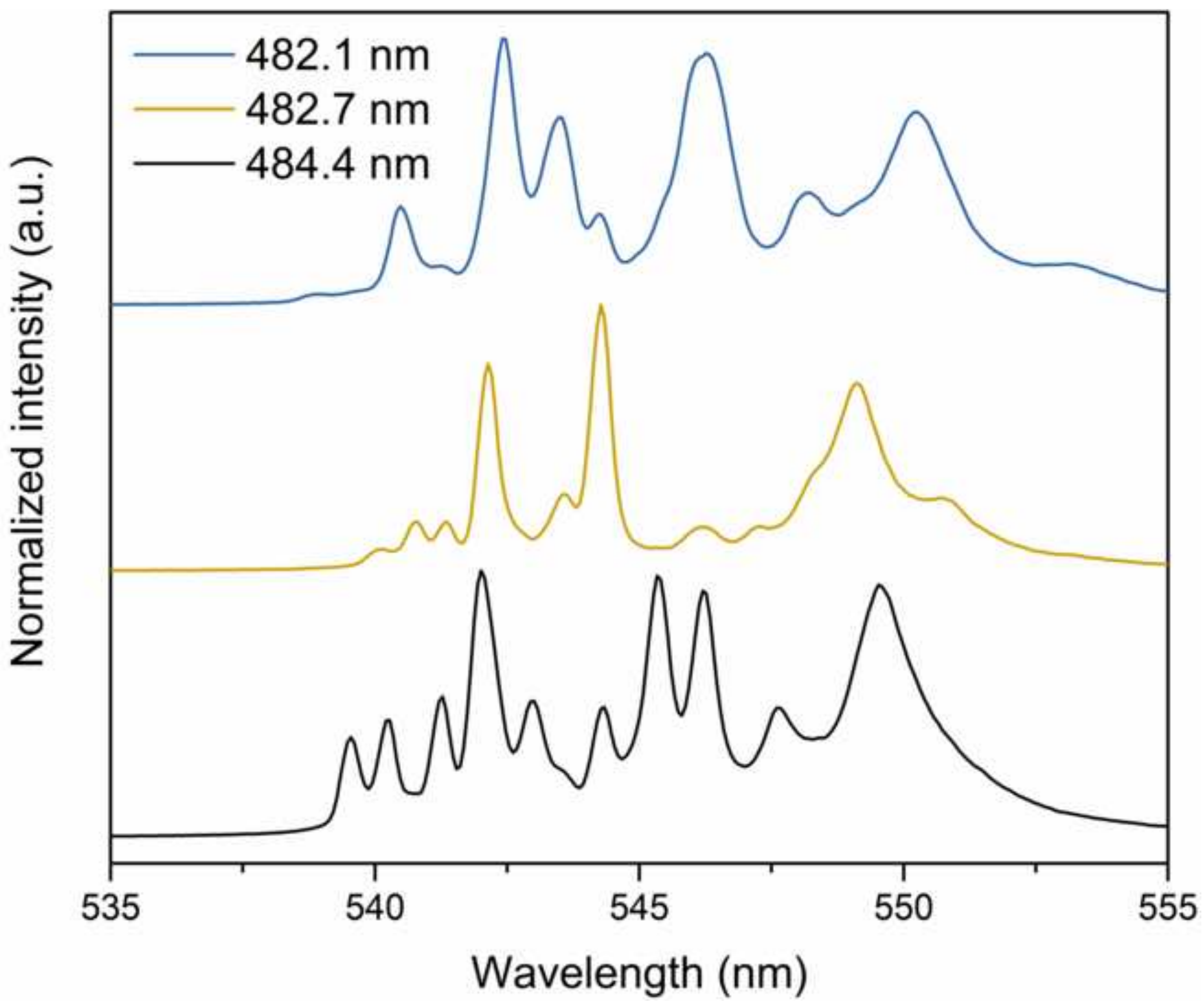

